\title{
Soft Computing and Multi-Scal Model Technics to Predict the Early Age Compression Strength of Cement Paste as a Function of Polymer Contents, Water-to-Cement-Ratio, and Curing Ages
}

Ahmed Mohammed ( $\nabla$ ahmed.mohammed@univsul.edu.iq)

University of Sulaimani https://orcid.org/0000-0003-4306-3274

Kawan Ghafor

University of Sulaimani

Wael Mahmood

University of Sulaimani

Warzer Sarwar

University of Sulaimani

Lajan Burhan

University of Sulaimani

\section{Research Article}

Keywords: Cement paste, Polymer contents, Strength, Statistical analysis, Modelling.

Posted Date: November 18th, 2021

DOI: https://doi.org/10.21203/rs.3.rs-1078868/v1

License: (c) (1) This work is licensed under a Creative Commons Attribution 4.0 International License.

Read Full License 


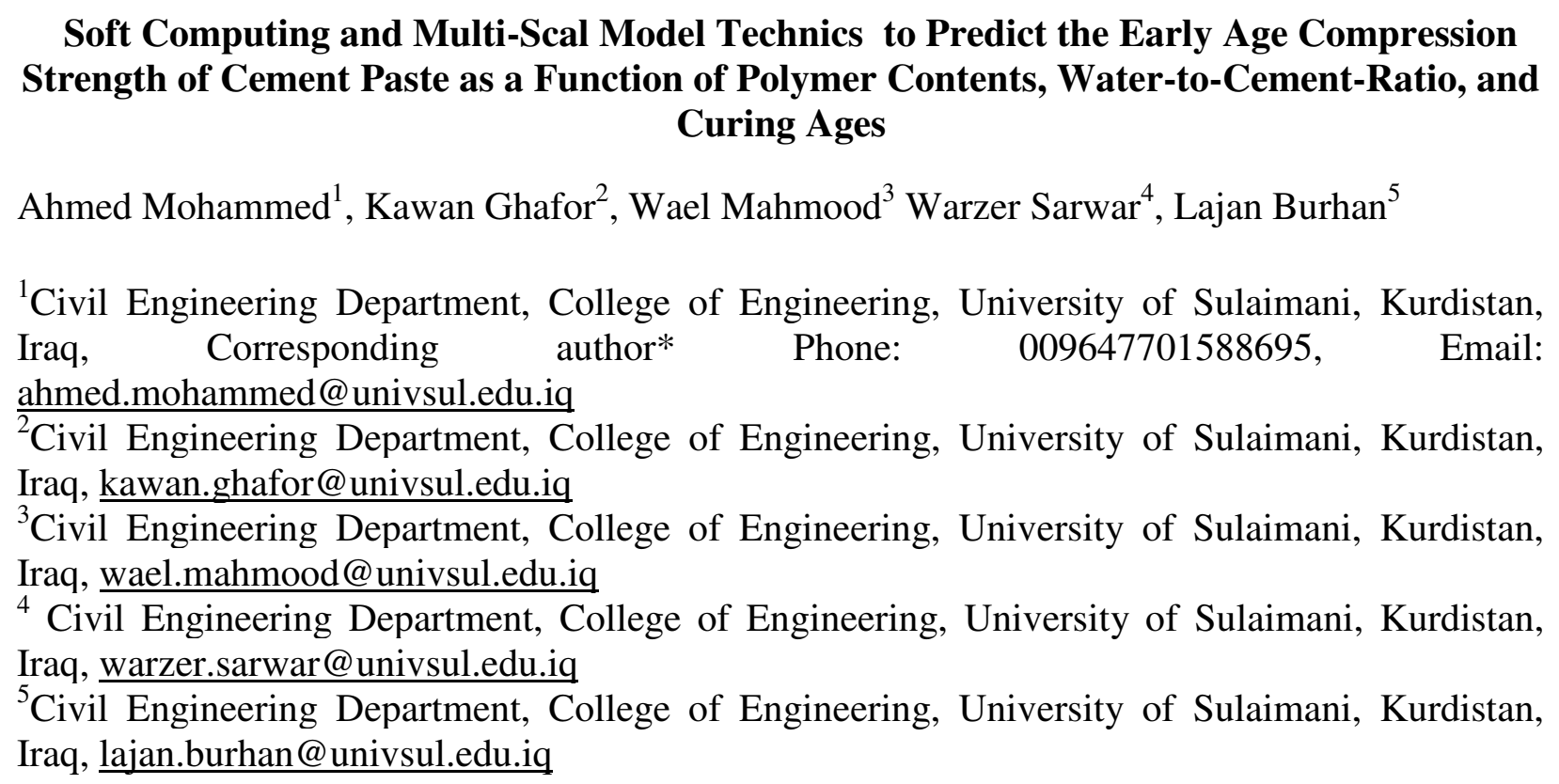

\section{Abstract}

In this study, the effect of two water reducer polymers with smooth and rough surfaces on the compression strength of Ordinary Portland cement (OPC) was investigated. Three different initial ratios between water and cement (w/c) 0.5, 0.6, and 1 were used in this study. The amount of polymer contents varied from 0 to $0.06 \%$ (\%wt) for the cement paste with initial w/c of 0.5 and the polymer contents ranged between 0 to $0.16 \%(\% \mathrm{wt})$ for the cement paste with initial w/c of 0.6 and 1 were investigated. SEM test was conducted to identify the impact of polymers on the behavior of cement paste. The compression strength of OPC cement was increased significantly with increasing the polymer contents. Because of a fiber net (netting) around cement paste particle was developed when the polymers were added to the cement paste which leads to decrease the void between the particles, binding the cement particles, therefore, increased the viscosity and compression strength of the cement rapidly. In this analysis, the hardness of cement paste with polymer contents has been evaluated and modeled using four different model technics. More environmentally sustainable construction, and lower cost than 
conventional building materials and early age strengths of the cement. To overcome the mentioned matter, this study aims to establish systematic multiscale models to predict the compression strength of cement paste containing polymers and to be used by the construction industry with no theoretical restrictions. For that purpose, a wide data a total of 280 tested cement paste modified with polymers, has been conducted, analyzed, and modeled. Linear, Nonlinear regression, M5P-tree, and Artificial Neural Network (ANN) technical approaches were used for the qualifications. In the modeling process, the most relevant parameters affecting the strength of cement paste, i.e. polymer incorporation ratio (0-0.16\% of cement's mass), waterto-cement ratio (0.5-1), and curing ages (1 to 28 days). According to the correlation coefficient (R), mean absolute error and the root means a square error, the compression strength of cement paste can be well predicted in terms of w/c, polymer content, and curing time using four various simulation techniques. Among the used approaches and based on the training data set, the model made based on the Non-linear regression, ANN, and M5P-tree models seem to be the most reliable models. The sensitivity investigation concludes that the polymer content is the most dominating parameter for the prediction of the compression strength of cement paste with this data set.

Words of key: Cement paste; Polymer contents; Strength; Statistical analysis; Modelling.

\section{Introduction}

Cement plays an adhesive role in binding materials used in Construction Engineering. Cement is widely used in construction and well-cemented oil fields. Cement alone (neat) can be used as grouting, mortar and concrete processing, pipe joints, and foundation preparation [1]. Calcium (sand or clay), aluminum, and iron are the main raw materials for cement production. The chemical properties of the cement and its time change provide insight into the strength of the 
cement system and the chemical properties of cement [2, 3, 4]. A variety of byproduct products used in many comprehensive research trials to alter the properties of cement-based concrete such as slag, calcinated clay, calcined clay, fuel ash, husk ash, soil granulated furnace slag, and metakaolin $[8,11-15]$. Polycarboxylates were utilized to modify concrete by accelerator or to delay the setting time following the desired project to increase the viscosity and mechanical behavior in liquid and solid phases by reducing water mixing [16-18]. The addition of polymeric additives to the cement grid optimizes the viscosity, fluidity, and strength properties through the development of an electrostatic distaste and stress-causing deflocculating [18-20]. The application of small amounts of polymer admixture in cement increases the water content needed to achieve the desired flowability $[21,22]$. When the cement layer has been in contact with water molecules, polycarboxylate, and other ions are found in the saturation zone [18]. The mixing water and cement particles adsorption on the interface has been fixed by polycarboxylate ether molecules that cause a negative charge around each cement particle [19-24].

There are several methods for modeling the properties of materials, including computational modeling, statistical techniques, and recently developed tools such as regression analyses and Artificial Neural Networks (ANN) [25, 26]. Multilinear regression analysis, M5P-tree, and ANN are techniques widely used to solve problems in construction project applications [27-38]. The most important characteristics of ANN is the ability to learn directly from examples and the great response to imperfect tasks. An ANN, as opposed to traditional programming-based computing, is a mathematical model or a computational model based on brain-like learning. The model consists of interconnected artificial neuron groups that stimulate the brain structure to store and use knowledge and process information using a connectionist approach [39-41]. Feedforward networks, also known as multilayer perceptron, are the most common ANN models for many 
applications. Most of the attempts have been related to a single scale model without covering a wide experimental data or multiple parameters [42, 43, 44]. Thus, the effect of several parameters such as the polymer content, w/c and curing time of 1 day up to 28 days was quantified using different model techniques, namely linear and non-linear regressions, M5P-tree and ANN-based approaches for predicting the compression strength of cement paste using 280 tested samples.

\subsection{Research significant}

The main objective of this study is to propose systematic multiscale models to predict the compression strength of cement paste containing polymers. Thus, a wide experimental data (280 tested samples with different polymer contents, curing period and ratio between water to cement) was considered with different analysis approaches (i) to guarantee the construction industry to use the proposed models without any theoretical; (ii) to perform a statistical analysis and understand the effect of the composition of the cement paste such as polymer content, and the ratio between water to cement on the compression strength of the cement paste; (iii) to quantify and propose a systematic multiscale model to predict the compression strength of cement paste containing small amounts of polymers (up to $0.16 \%$ ) with various water-to-cement ratio and curing time up to 28 days; (iv) to find the most reliable model to predict the compression strength of cement paste from four different model techniques (linear, nonlinear relations, M5Ptree, and ANN models.) using statistical evaluation parameters.

\section{Methodology}

The tests were conducted following ASTM and British standards. For each case, an average of three samples is considered.

\subsection{Ordinary Portland Cement}


In this research, the Ordinary Portland Cement (OPC) from the Gasin Cement Company was used. The chemical and mineralogical components of the cement used are shown in Fig. 1. Based on the SEM test the cement particle size was varied between $14.4 \mu \mathrm{m}$ to $42 \mu \mathrm{m}$ as shown in Fig. 2(a).

\subsection{Polymers}

Two types of water-reducing polymer (Synthetic powder) were used. The commercial label of the used polymers is DBC-21(Polymer 1) and VK-98 (Polymer 2). The properties of the two types of polymer are listed in Table 1. From the SEM test, the polymer 1 had a rough or fibers surface (Fig. 2(b)) while the polymer 2 had a smooth surface (Fig. 2(c)). The polymer particles have an attractive property to each other and the particles of different materials.

\subsection{X-ray}

Analysis of the composition of chemical substances of cement at $25^{\circ} \mathrm{C}$ was conducted for X-ray diffraction (XRD). The XRD pattern of particles was obtained by a Siemens D5000 X-ray diffraction system. The samples were analyzed by using parallel beam optics with $\mathrm{CuK} \alpha$

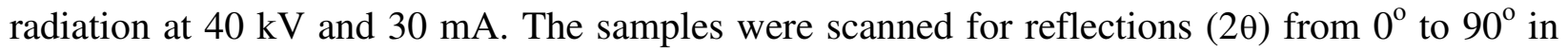
steps of $0.02^{\circ}$ and $2 \mathrm{sec}$ count time per step. XRD was undertaken to detect the major chemical and mineralogical component of cement. The main chemical and mineralogical formulation in the cement included $\mathrm{C}_{3} \mathrm{~S}, \mathrm{C}_{2} \mathrm{~S}, \mathrm{C}_{3} \mathrm{~A}, \mathrm{C}_{4} \mathrm{AF}$, and Quartz, $\left(\mathrm{SiO}_{2}\right)$ (see Fig. 1).

\subsection{Scanning Electron Microscope (SEM)}

An SEM quantum 400 from FEI Company was used in this paper. It is a high-resolution field emission gun scanning electron microscope appropriate for imaging and analysis of nano-scale size. The samples were prepared and put the specimen on the surface of the stamp. The conductive tape was used on the surface of the stamp. The sample holder was seated into the 
appropriate hole on the sample holder mount. The polymers and cement are tested in powder condition and the cement modified with polymers was tested after 7 days of curing.

\subsection{Fluidity}

The fluidity of cement slurry was measured using the ASTMC-230 mini-slump cone testing method. The top, bottom, and height of the cone respectively are $70 \mathrm{~mm}, 100 \mathrm{~mm}$, and $60 \mathrm{~mm}$. The cement slurry distribution was $191 \mathrm{~mm}$ for a water-cement ratio of 0.5 . The addition of polymers decreased the water content of cement slurries but increased their fluidity by $7-26 \%$ depending on the polymer type, the polymer percentage, and the amount of water-cement.

\subsection{Standard consistency test}

The purpose of this study is to determine the minimum water mix to measure the initial chemical reaction between water and cement. Cement is one of the products that require the right amount of water to reach the requisite strength of cement. The norm accuracy was obtained based on the standard EN 196-3. Polymers to reduce the amount of water required to achieve the same quality (Fig. 3).

\subsection{Compression strength (ASTM C349)}

The cement paste after mixing is lined with cubic molds with a height of $(4 \mathrm{x} 4 \mathrm{x} 16) \mathrm{cm}^{3}$. The cement paste put into the mold in one layer. After that, the mold is leveled and covered with a plastic bag and stored at room temperature. After 24 hours the specimens were removed and placed in the water at room temperature and 95 percent humidity, until the testing time. Samples

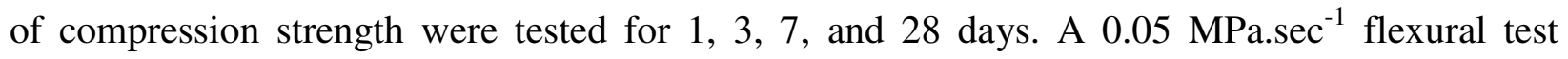
machine was used to separate the specimen into two parts and compressed each element at the speed of 0.2 MPa.sec ${ }^{-1}$ using a compression machine (Fig.4) [45-52]. 


\subsection{Modeling}

The total tested of data (280 observations) was analyzed and divided into two groups. The larger group included 187 data used to create models, while the other group included 93 data used to validate models $[53,54]$. The input data set consists of the water to cement ratio $(\mathrm{w} / \mathrm{c})$ the curing age ( $\mathrm{t}$, days), and the polymer content $(\mathrm{P}, \%)$, while the tested compression strength (MPa) for the cement paste was used as a target. The following models (sections $2.8 .1-2.8 .4$ ) were used to assess the impact of the mentioned parameters on the compression strength of the cement paste.

\subsubsection{Linear Approach (LR) Model}

LR model can be considered one of the most common regression equations (Eq.1) for the prediction of cement [55].

$\sigma c=a+b *(w / c)$

where, $\sigma c, \frac{w}{c}, a, \& b$ denote compression strength of cement paste (MPa), water to cement ratio, and equation parameters, respectively. However, other cement paste components factors affecting the compression strength, the type of cementitious materials, and curing time are not included in the equation. To have more reliable results, Eq. 2 is proposed to include other factors.

$\sigma c=a+b *(w / c)+c *(t)+d *(P)$

Where: w/c is a water-to-cement ratio, $\mathrm{t}$ is curing age (days), and the Polymer content (P, \%), respectively, and the parameters of the model are a, b, c, and d. In compliance with Eq. 2, all the variables seem to be adapted with linear (Eq. 1) extent. Nevertheless, this may not necessarily be occurred for all cases because the variables involved in a cement paste mix may affect its compression strength and interrelate with each other. Thus, it always needs to modify the model to reliably predict the compression strength of cement paste with acceptable high accuracy [5658]. Accordingly, Eq. 2 was converted to a multivariable power equation. 


\subsubsection{Nonlinear Regression Model (NLR)}

To develop a nonlinear regression model, the following formula (Eq. 3) can be considered as a general form [41-49]. Eq. 3 is representing the interrelation between the variables given in Eq. 2 and Eq. 3 to estimate the compression strength of the conventional and cement paste component.

$\sigma_{\mathrm{c}}=a *\left(\frac{w}{c}\right)^{b} *(t)^{c}+d *\left(\frac{w}{c}\right)^{e} *(t)^{f} *(P)^{g}$

\subsubsection{M5P-tree Model (M5P)}

M5P-tree is a genetic algorithm learner for regression problems, first introduced by a study [59]. This tree algorithm sets linear regression features on the terminal node and fits into a multivariate linear regression model on each sublocation by classifying or dividing different areas of data into multiple different-spaces. The M5P-tree approach is not discrete segments but rather constant class problems and can handle rather high dimensional functions. Reveals the data of every linear model component developed so that the nonlinear relationship of the data sets is approximated. Error estimation is presented with information on the M5P-tree model tree division criteria on each node. Errors measured by the default value variance of the class entering the node. The attribute that maximizes the expected error reduction is used to evaluate any function of that node. Information on the M5P-tree model tree dividing criteria is obtained based on error calculations per node. The M5P error is determined by the standard deviation of the class values at the node. The feature that maximizes the expected error reduction resulting from evaluating each attribute at that node is chosen for node division. Due to the branching method, child node data (subtree or smaller nodes) have less StDev. value. Parent nodes (greater nodes). After reviewing all possible structures, select a system with the highest potential error reduction. This division also creates a large tree-like structure that leads to overfitting. In the second step, 
194 the enormous tree is pruned, and the trimmed subtrees are replaced by linear regression 195 functions.

196

197

198

199

200

201

202

203

204

205

206

207

208

209

210

211

212

213

214

215

216

\subsubsection{Artificial intelligence (ANN)}

ANN is a computing system that simulates the processes and analyses of the human brain. Also, this model is a machine learning system used for various numerical predictions/problems in Construction Engineering [60, 61]. ANN includes the input layer, the hidden layer (one or more layers), and the output layer. The hidden layer is related by weight, transfer function, and bias to the other layers. A multi-layer feed-forward network was programmed with a mixture of proportions, w/c, curing time, and polymer content like inputs, and compression strength as output. There is no standard method for designing or selecting a network architecture. Therefore, the maximum number of hidden layers and neurons was calculated by the trial and error test based on the lowest average square error criterion. The second step of the optimal network design process was to choose the optimum number of epochs during the training that gave the minimum MAE and RMSE and high R-value. The same preliminarily designed networks with hyperbolic tangent transfer functions were used to see the effect of several epochs on reducing the MAE and RMSE. The MAE variations with the number of epochs are presented for the preliminarily designed networks. After designing the optimum architecture, the available data set (total of 280 data) was divided into two parts; the first part was $2 / 3$ of the overall data set (187) for training the network, the second part was $1 / 3$ of the total data set (93) for testing the network [62]. Several transfer functions and ANN structures with a varied number of hidden layers and neurons were tested to design the optimal network structure to predict the cement paste compression strength. Among the networks, two hidden layers with eleven neurons with two different neurons distributions and a hyperbolic tangent transfer function were chosen for the 
217 cement paste modified with polymer 1 and polymer 2 due to having the minimum mean absolute

218 error (MAE) as can be seen in Fig.5. In this part of the research, the ANN model was used to 219 estimate the compression strength of polymer-containing cement paste as a cement replacement, 220 w/c, curing time, and polymer contents.

221

222

224

\section{3. Analysis and outputs}

$M A E=\frac{\sum_{i=1}^{n}\left|\left(y_{i}-x_{i}\right)\right|}{N}$

$R M S E=\sqrt{\frac{\sum_{i=1}^{n}\left(y_{i}-x_{i}\right)^{2}}{N}}$

\subsection{Model performance assessment criteria}

Correlation coefficients (R), mean absolute error (MAE), and root means square error (RMSE) values were used to estimate the ability of the above-mentioned modeling methods. Three common statistical measures: R, MAE, and RMSE were used as performance evaluation metrics to determine the efficacy of machine learning techniques. Numerous experiments were performed to determine the optimal value of key parameters. High R values (Eq. 4) and lower MAE values (Eq. 5), RMSE (Eq. 6) show better model precision.

$R=\frac{N \sum y i x i-\left(\sum y i\right)\left(\sum x i\right)}{\sqrt{N\left(\sum\left(y i^{2}\right)-\left(\sum\left(y i^{2}\right)\right.\right.} \sqrt{N\left(\sum\left(x i^{2}\right)-\left(\sum\left(x i^{2}\right)\right.\right.}}$

$\mathrm{yi}=$ tested data; $\mathrm{xi}=$ predicted data; $\bar{y}=$ mean value of $\mathrm{yi}$; and $\mathrm{N}$ is the data set.

\subsection{Scanning electron microscope}

The results for the OPC, polymers, and cement paste, modified with 0,06 percent polymers, were tested using a Scanning Electron Microscope (SEM) at seven days of curing (Fig. 5). Based on the SEM test analysis, the polymers samples were amorphous [63]. Fig. 2(a) showed that the cement particle size has varied particle sizes ranging between $14.4 \mu \mathrm{m}$ to $42 \mu \mathrm{m}$. Fig. 2(b) showed that most of the polymer 1 particles reposed of near-spherical with rough or fibers 
surfaces. Most of polymer 2 particles also consisted of near-spherical but were very smooth as compared to polymer 1 (Fig. 2(c)).

\subsection{Consistency}

Consistency is called the required amount of water combined to cause the chemical initial reaction between water and cement. The use of polycarboxylate polymer on cement paste limited the water that was needed to reach the required fluidity using mini-slump cone test outcomes. The application of polymers (1\&2) and cement decreased the needed water by 3 to 14 percent, respectively, to the normal consistency. Polymers reduced water content by $24 \%$ to $66.3 \%$ depending on the polymer type, polymer density (contains), fluidity, and w/c. The addition of $0.12 \%$ of polymer lowered w/c by $38 \%$ to $56 \%$ depending on the types of polymer, w/c, and fluidity forms. The flow of cement paste was $290 \mathrm{~mm}$ and $430 \mathrm{~mm} \mathrm{w} / \mathrm{c} 0.6$ and 1 respectively while adding polymer simultaneously reducing the water content of cement paste and increasing the fluidity by 1 to $8 \%$ depending on polymer type, polymer content and w/c.

\subsection{Water reducing, $(\mathrm{WR})$}

From the mini-slump, cone test results adding polycarboxylate polymer to the cement slurry reduced the water required to reach the desired flowability. The addition of polymers reduced the water content by $12.5 \%$ to $46.3 \%$ depending on the type of polymer, polymer percent, and fluidity. The water to cement ratio of control sample 0.5 . An additional of $0.04 \%$ of polymer reduced the water-cement ratio by $25 \%$ to $32.5 \%$ depending on the types of polymer, watercement-ratio, and fluidity (Fig. 3 a). Based on the results of mini-slump cone tests, the addition of polycarboxylate polymer to cement decreased the water needed for the fluidity necessary. The addition of $0.12 \%$ polymer decreased the w/c by $38 \%$ to $56 \%$ based on the types of polymers, w/c, and fluidity shown in Fig. 3(b). 


\subsection{Compression strength}

The additional polymers were highly affected by increasing the compression strength $\left(\sigma_{\mathrm{c}}\right)$ of cement paste up to 28 days of curing. With the increase in the percentage of polymer ( $\mathrm{P} \%)$ the compression strength of cement paste is nonlinearly increased. At 1 day of curing an additional of $0.06 \%$ of polymer 1 and 2 improved the compression strength of cement paste by $224 \%$ and $140 \%$ respectively. The addition of $0.06 \%$ of polymer improved the $\sigma_{\mathrm{c}}$ of cement paste by $84 \%$ and $224 \%$ based on the types of polymer, water-cement ratio, and curing period. The improvement is due to the presence of amorphous gel that filling spaces between cement particles with fiber nets (netting) around the cement particles which lead to decrease voids and binding the cement particle together leading to an increase in the compression strength of cement paste (Fig. 7). For the initial w/c of 0.6 and 1 respectively, the compression strength of the cement paste on 1 day of cure was 5.92 $\mathrm{MPa}$ to $3.98 \mathrm{MPa}$. With $0.08 \%$ addition of $\mathrm{P} 1$ and $\mathrm{P} 2$, the compression strength of cement pastes improved by $90 \%$ to $544 \%$, based on the polymer content, type of polymer, and w/c (Fig. 7 and Fig. 8). By adding $0.16 \%$ P1 and P2 the compression strength of the cement paste was raised by $229 \%$ to $361 \%$ at 28 days of treatment based on polymer content and w/c (Fig. 7, Fig. 8, and Fig. 9). The experimental results show that the presence of polymers in cement paste increases the compression strength of the cement paste with confidence. The strength increases were due to the dispersal of cement particles and the tensile bonding of particles, resulting in a reduction in the porosity and void ratio of cement paste $[52,63]$. 


\subsection{The relation between calculated and actual cement paste compression strength}

\section{(a) The linear model (LR)}

The model parameter observed that the w/c significantly decrease cement paste's compression strength. Table 2 summarizes model parameters, R, MAE and RMSE, and data number. The relationships between actual and calculated compression strength of the cement paste are shown in Fig. 10. The research dataset contains a $\pm 35 \%$ and $\pm 30 \%$ error lines for the cement paste treated with polymers $(1 \& 2)$ respectively, indicating that most checked results are in $\pm 35 \%$ and $30 \%$ error lines, respectively (Fig. 10). Nevertheless, the model slightly underestimated the strength cement paste ranged between $20 \mathrm{MPa}$ to $40 \mathrm{MPa}$ mixes.

$\sigma_{C}=-50.25-63.85 * \frac{w}{c}+1.06 * t+100.86 * P_{1}$

No. of data $=187, \mathrm{R}=0.794, \mathrm{RMSE}=14.159 \mathrm{MPa}$

$\sigma_{\mathrm{c}}=50.47-57.63 * \frac{\mathrm{w}}{\mathrm{c}}+0.86 * \mathrm{t}+95 * \mathrm{P}_{2}$

No. of data $=187, \mathrm{R}=0.802, \mathrm{RMSE}=12.839 \mathrm{MPa}$

And from model parameters in the Eq. 7 and Eq.8, It can be inferred that the polymer content has the highest impact on the compression strength of other w/c and curing time. According to equation variables in the Eq.7 and Eq. $8(\mathrm{~d}=100.86$ and $\mathrm{d}=95)$, Polymer 1 was much more successful than polymer 2 for increasing the strength of the cement paste compression and the simulation results with the same experimental results.Eq.7 and Eq.8 were also checked with the research dataset as seen in Fig. 11.

\section{(b) Nonlinear Regression (NLR) Model}

The model parameter shows that cement content significantly influences cement paste's compression strength. Clear relationships between calculated and actual compression strength 
can be seen in Fig. 12. The study training dataset contains an error line of $\pm 25 \%$ for the compression strength of the cement paste modified with $\mathrm{P} 1$ and $\mathrm{P} 2$, indicating that almost all checked results are in $\pm 25 \%$ error lines. This model seems to be more reliable than LR to predict the compression strength of cement paste.

$\sigma_{\mathrm{C}}=10.55 * \frac{w}{c}^{-0.56} * t^{0.26}+3.37\left(\frac{t^{0.18} * P 1^{0.21}}{\frac{w^{1.96}}{c}}\right)$

No. of data $=187, \mathrm{R}=0.961, \mathrm{RMSE}=6.396 \mathrm{MPa}$

$\sigma_{c}=12 *\left(\frac{t^{0.21}}{\frac{w^{0.52}}{c}}\right)+3.21 *\left(\frac{t^{0.18} P 2^{0.31}}{w / c^{2.14}}\right)$

No. of data $=187, \mathrm{R}=0.924, \mathrm{RMSE}=8.235 \mathrm{MPa}$

Focusing on model parameters Eq.9 and Eq. 10, the maximum influence of polymer contents on increasing compression strength relative to other cement paste compositions can be obtained. Also based on the model parameters in the Eq.9 and Eq. $10(d=3.37$ and $d=3.21)$, the polymer 1 was also more productive than the polymer 2 for enhance compression strength of the cement paste the similar observation was made in the experimental work. Eq. 9 and Eq.10 have also been validated using the testing dataset (Fig. 13).

\section{(c) M5P-tree model}

Fig. 14 shows the division of input space $\mathrm{x}_{1}, \mathrm{x}_{2}$ (independent variables) by the M5P-tree model algorithm into nine linear tree regression functions (marked LM1 through LM5). The model's general shape is $y=a o+a 1 x 1+a 2 \times 2$, where ao, $\mathrm{a}_{1}$, and $\mathrm{a}_{2}$ are linear regression constants. Fig.14 indicates the tree-shaped branch relationship and the model (Eq. 11) parameters are summarized in Table 3. The research dataset contains an error line of $\pm 30 \%$ for the compression strength of the cement paste modified with $\mathrm{P} 1$ and $\mathrm{P} 2$, indicating that almost all measured results are in $\pm 30 \%$ error lines (Fig. 15). Furthermore, the output of this model is more reliable than 
327 those of the previous models. In other words, the calculated and actual compression strength of 328 the cement paste is adapted with the line of equality.

$329 \sigma c=a *\left(\frac{w}{b}\right)+b *(t)+c *(P 1)+d$

330 No. of Data $=187, \mathrm{R}=0.950, \mathrm{RMSE}=7.354 \mathrm{MPa}$

$331 \sigma c=a *\left(\frac{w}{b}\right)+b *(t)+c *(P 2)+d$

332

No. of Data=187, $\mathrm{R}=0.923, \mathrm{RMSE}=8.274 \mathrm{MPa}$

The model parameters $(a, b, c$ and $d)$, are listed in Table 3 and based on the linear tree registration function (LM num:) the model variables will be selected. The models (Eq. 11 and Eq. 12) have also been evaluated using the testing dataset as can be seen in Fig. 16.

\section{(d) ANN Model}

The network was equipped with the training data set, accompanied by the test data to predict the compression strength values for the correct input parameters (Fig. 4). A sensitivity test for the model predictions was also carried out for the cement paste modified with P1 and P2 (Fig. 17).

The ANN model based on the predictions over-predicted 93 of the data analyzed. A trial and error cycle is the development of the ANN model (such as the number of hidden layer neurons, number of hidden layers, momentum, learning rate, and iteration). The ANN model contains two hidden layers for both polymers modified cement paste. Hidden layers contain 11 neurons and three inputs with momentum $=0.2$, learning rate $=0.1$ and Iteration $=2000$. The main concept to generate data based on the ANN model is shown in Fig. 17. As summarized in Table 2, the ANN model was obtained $\mathrm{R}=0.986, \mathrm{MAE}=3.909 \mathrm{MPa}$, and $\mathrm{RMSE}=4.743 \mathrm{MPa}$ for the cement paste modified with polymer 1 and $\mathrm{R}=0.961, \mathrm{MAE}=4.309 \mathrm{MPa}$, and $\mathrm{RMSE}=5.996 \mathrm{MPa}$ for the cement paste modified with polymer 2 . The research dataset contains an error line of $\pm 20 \%$ for both cement paste modifications, indicating that all measured results are in $\pm 20 \%$ error lines. 
The compression strength values calculated and the ANN expected are compared and validated with the testing dataset in Fig. 17 and Fig.18. Overall, based on the results shown in Table 2 and Fig. 17 and Fig.18, the accuracy of the ANN model is suitable for the prediction of compression strength. Inter-comparison regression and soft computing-based models: Overall comparison among Regression and soft computing-based models (Table 2) suggests that the ANN-based model performs better than other applied models. NLR model is working better than the LR model for this data set. Fig. 19 indicate the agreement plot and performance diagram both figures suggest that the NLR and ANN-based model is outperforming than other applied models with minimum deviation from agreement line or actual values. Three statistic parameters including standard deviation, correlation, and root mean square error, evaluated the degree of compliance of cement paste's compression strength among actual and predicted values.

\section{Sensitivity investigation}

A comparison between the sensitivity of the models was performed to evaluate the most important input variable when calculating the cement paste's compression strength. Several training data sets were created by extracting the single input variable at a time, and the test data set reported the effects of R, MAE, and RMSE. Data set to split into two sections for training and testing. The best performing model is selected for the sensitivity analysis. In this study, the ANN-based model is used for sensitivity analysis. Results obtained from Table 4 indicate that the polymer content is the most influencing parameter for the prediction of compression strength using the M5Ptree-based model.

\section{Conclusions}


371 Based on the tested data and the simulation of the compression strength of cement paste at 280

372 different ratios between the water and the cement, polymer content, and curing ages, the

373 following conclusions are drawn.

374 1. The compression strength of cement increased by $84 \%$ to $360 \%$ depending on the curing 375 time, water-cement ratio, curing time, and polymer contents. Based on NLR parameters, 376 polymer 1 (rough surfaces) had the highest impact on increasing the compression strength of 377 cement paste as compared to polymer 2 (smooth surfaces). This improvement of compression 378 strength was due to the dispersion of cement particles and increasing the friction between the particles that lead to reduce the void ratio and increasing the density of cement paste.

2. From the SEM test analysis, the addition of the polymer produced a fiber net (netting) around cement particle which leads to decrease void, binds the cement particles together, and increased the compression strength of cement paste.

3. The designed ANN was used to predict the cement paste strength after it was trained by $2 / 3$ of the 280 tested data. The ANN model predicted the compression strength of the testing data

4. Apart from the standard curing age, the results of this study have shown that the ANN model is capable of predicting the $28^{\text {th }}$-days compression strength of cement paste. Based on the training and testing data sets, the ANN and NLR models predicted the compression strength very close to experimental data and the predictions were better than other models. 
402

403

404

405

406

407

408

409

410

411

412

413

414

5. Sensitivity analysis showed that polymer content is the most important parameter for predicting the compression strength of cement paste using the M5P-based model.

\section{Data Availability Statement}

No data, models, or codes were generated or used during the study.

\section{Acknowledgment}

The Civil Engineering Department, University of Sulaimani, Gasin Cement Co. and Zarya Construction Co. supported this study.

\section{Funding Information}

No fund was received.

\section{Conflicts of Interest Statement}

None

\section{References}

1. Amer, A. A., El-Sokkary, T. M., \& Abdullah, N. I. (2015). Thermal durability of OPC pastes admixed with nano iron oxide. HBRC Journal, 11(2), 299-305.

2. Kırg1z, M. S. (2016). Strength gain mechanism for green mortar substituted marble powder and brick powder for Portland cement. European Journal of Environmental and Civil Engineering, 20(sup1), s38-s63.

3. Ashikhmen, V. A., \& Pronina, L. É. (1986). Rheological properties of dispersed cement grouts. Power Technology and Engineering (formerly Hydrotechnical Construction), 20(10), 598-603.

4. Rosquoët, F., Alexis, A., Khelidj, A., \& Phelipot, A. (2003). Experimental study of cement grout: Rheological behavior and sedimentation. Cement and Concrete Research, 33(5), 713-722. 
5. Christodoulou, D. N., Droudakis, A. I., Pantazopoulos, I. A., Markou, I. N., \& Atmatzidis, D. K. (2009). Groutability and impact iveness of microfine cement grouts.

6. Lim, S. K., Tan, C. S., Chen, K. P., Lee, M. L., \& Lee, W. P. (2013). effect of different sand grading on strength properties of cement grout. construction and Building materials, 38, 348-355.

7. Benyounes, K., \& Benmounah, A. (2014). Impact of bentonite on the rheological behavior of cement grout in presence of superplasticizer. International Journal of Civil, Architectural, Structural and Construction Engineering, 8(11), 1095-1098.

8. Chen, J. J., Li, L. G., Ng, P. L., \& Kwan, A. K. H. (2017). Impact s of superfine zeolite on strength, flowability and cohesiveness of cementitious paste. Cement and Concrete Composites, 83, 101-110.

9. Mohammed, A., Raof and H., Salih. (2018). Vipulanandan Constitutive Models to Predict the Rheological Properties and Stress-Strain Behavior of Cement Grouts Modified with Metakaolin. Journal of Testing and Evaluation, 48(5).

10. Kirgiz, M. S. (2011). Chemical properties of blended cement pastes. Journal of Construction Engineering and Management, 137(12), 1036-1042.

11. Kirgiz, M. S. (2015). Strength gain mechanisms of blended-cements containing marble powder and brick powder. KSCE journal of civil engineering, 19(1), 165-172.

12. Kirgız, M. S. (2016). Fresh and hardened properties of green binder concrete containing marble powder and brick powder. European Journal of Environmental and Civil Engineering, 20(sup1), s64-s101.

13. Kirgiz, M. S. (2015). Advance treatment by nanographite for Portland pulverised fly ash cement (the class F) systems. Composites Part B: Engineering, 82, 59-71. 
14. Al-Martini, S., \& Nehdi, M. (2007). Impact of chemical admixtures on rheology of cement paste at high temperature. Journal of ASTM international, 4(3), 1-17.

15. Soroka, I., \& Ravina, D. (1998). Hot weather concreting with admixtures. Cement and Concrete Composites, 20(2-3), 129-136.

16. Konsta-Gdoutos, M. S., Metaxa, Z. S., \& Shah, S. P. (2010). Multi-scale mechanical and fracture characteristics and early-age strain capacity of high-performance carbon nanotube/cement nanocomposites. Cement and Concrete Composites, 32(2), 110-115. https://doi.org/10.1016/j.cemconcomp.2009.10.007

17. Cheung, J., Jeknavorian, A., Roberts, L., \& Silva, D. (2011). Impact of admixtures on the hydration kinetics of Portland cement. Cement and concrete research, 41(12), 1289-1309. https://doi.org/10.1016/j.cemconres.2011.03.005

18. Ezziane, K., Ngo, T. T., \& Kaci, A. (2014). Evaluation of rheological parameters of mortar containing various amounts of mineral addition with polycarboxylate superplasticizer. Construction and Building $\quad$ Materials, 70, 549-559. https://doi.org/10.1016/j.conbuildmat.2014.07.111

19. Jolicoeur, C., \& Simard, M. A. (1998). Chemical admixture-cement interactions: phenomenology and physico-chemical concepts. Cement and Concrete composites, 20(23), 87-101. https://doi.org/10.1016/S0958-9465(97)00062-0

20. Plank, J., \& Hirsch, C. (2007). Impact of zeta potential of early cement hydration phases on superplasticizer adsorption. Cement and concrete research, 37(4), 537-542. https://doi.org/10.1016/j.cemconres.2007.01.007 
21. Gallias, J. L., Kara-Ali, R., \& Bigas, J. P. (2000). The effect of fine mineral admixtures on water requirement of cement pastes. Cement and concrete research, 30(10), 15431549. https://doi.org/10.1016/S0008-8846(00)00380-X

22. Khudhair MH, Elharfi A, El-Youbi MS (2018) The effect of Polymeric Admixtures of Water Reduce of Superplasticizer and Setting Accelerator on Physical Properties and Mechanical Performance of Mortars and Concretes. J Environ Res Vol.1: No.1: 4.

23. Mikanovic, N., \& Jolicoeur, C. (2008). Influence of superplasticizers on the rheology and stability of limestone and cement pastes. Cement and concrete research, 38(7), 907-919. https://doi.org/10.1016/j.cemconres.2008.01.015

24. Khudhair, M. H. R., Elyoubi, M. S., \& Elharfi, A. (2017). Study of the influence of water reducing and setting retarder admixtures of polycarboxylate "superplasticizers" on physical and mechanical properties of mortar and concrete. https://doi.org/10.26872/jmes.2018.9.1.7.

25. Mohammed, A. S. (2018). Vipulanandan model for the rheological properties with ultimate shear stress of oil well cement modified with nanoclay. Egyptian Journal of Petroleum, 27(3), 335-347.

26. Sihag, P., Jain, P., \& Kumar, M. (2018). Modelling of impact of water quality on recharging rate of storm water filter system using various kernel function-based regression. Modeling earth systems and environment, 4(1), 61-68

27. Mohammed, A., Raof and H., Salih. (2018). Vipulanandan Constitutive Models to Predict the Rheological Properties and Stress-Strain Behavior of Cement Grouts Modified with Metakaolin. Journal of Testing and Evaluation, 48(5). 
28. Vipulanandan, C. \& Mohammed, A. (2019). Magnetic Field Strength and Temperature Effects on the Behavior of Oil Well Cement Slurry Modified with Iron Oxide Nanoparticles and Quantified with Vipulanandan Models. Journal of Testing and Evaluation, 48(6).

29. Mohammed, A. S. (2018). Vipulanandan models to predict the electrical resistivity, rheological properties and compression stress-strain behavior of oil well cement modified with silica nanoparticles. Egyptian journal of petroleum, 27(4), 1265-1273.

30. Mohammed, A. S. (2017). Effect of temperature on the rheological properties with shear stress limit of iron oxide nanoparticle modified bentonite-drilling muds. Egyptian journal of petroleum, 26(3), 791-802.

31. Mohammed, A., \& Vipulanandan, C. (2018). Smart cement compression piezoresistive, stress-strain, and strength behavior with nanosilica modification. Journal of Testing and Evaluation, 47(2).

32. Vipulanandan, C., Krishnamoorti, R., Mohammed, A., Boncan, V., Narvaez, G., Head, B., \& Pappas, J. M. (2015). Iron nanoparticle modified smart cement for real time monitoring of ultra-Deepwater oil well cementing applications. In Offshore Technology Conference. Offshore Technology Conference.

33. Mohammed, A. S. (2014). Characterization and Modeling of Polymer-Treated and Nano Particle Modified Sulfate Contaminated Soils, Drilling Muds, and Hydraulic Fracturing Fluids under Groundwater (Doctoral dissertation).

34. Mohammed, A. S. (2018). Electrical resistivity and rheological properties of sensing bentonite-drilling muds modified with lightweight polymer. Egyptian Journal of Petroleum, 27(1), 55-63. 
35. Vipulanandan, C., \& Mohammed, A. (2015). Effect of nanoclay on the electrical resistivity and rheological properties of smart and sensing bentonite drilling muds. Journal of Petroleum Science and Engineering, 130, 86-95.

36. Vipulanandan, C., Mohammed, A., \& Ganpatye, A. S. (2018). Smart Cement Performance Enhancement with $\mathrm{NanoAl}_{2} \mathrm{O}_{3}$ for Real Time Monitoring Applications Using Vipulanandan Models. In Offshore Technology Conference. Offshore Technology Conference.

37. Vipulanandan, C., \& Mohammed, A. (2015). Hydraulic Fracturing Fluid Modified with Nanosilica Proppant and Salt Water for Shale Rocks. AADE National Technical Conference and Exhibition. AADE-15-NTCE-38.

38. Saridemir, M. (2009). "Prediction of Compression Strength of Concretes Containing Metakaolin and Silica Fume by Artificial Neural Networks.” Advances in Engineering Software, 40, 350-355.

39. Mohammed, A. S. (2018). Property correlations and statistical variations in the geotechnical properties of $(\mathrm{CH})$ clay soils. Geotechnical and Geological Engineering, 36(1), 267-281.

40. Vipulanandan, C., \& Mohammed, A. (2020). Effect of drilling mud bentonite contents on the fluid loss and filter cake formation on a field clay soil formation compared to the API fluid loss method and characterized using Vipulanandan models. Journal of Petroleum Science and Engineering, 107029.

41. Yaman, M. A., Elaty, M. A., \& Taman, M. (2017). Predicting the ingredients of selfcompacting concrete using artificial neural network. Alexandria Engineering Journal, 56(4), 523-532. 
42. Vipulanandan, C., Mohammed, A., \& Ganpatye, A. S. (2018). Smart Cement Performance Enhancement with $\mathrm{NanoAl}_{2} \mathrm{O}_{3}$ for Real Time Monitoring Applications Using Vipulanandan Models. In Offshore Technology Conference. Offshore Technology Conference.

43. Mohammed, A., Mahmood, W., \& Ghafor, K. (2020). Shear stress limit, rheological properties and compression strength of cement-based grout modified with polymers. Journal of Building Pathology and Rehabilitation, 5(1), 3.

44. Demir, İ., Güzelkücük, S., \& Sevim, Ö. (2018). Effects of sulfate on cement mortar with hybrid pozzolan substitution. Engineering Science and Technology, an International Journal, 21(3), 275-283.

45. Vipulanandan, C., Mohammed, A., \& Qu, Q. (2014, April). Characterizing the hydraulic fracturing fluid modified with nano silica proppant. In AADE Fluids Technical Conference and Exhibition, Houston (pp. 15-16).

46. Abdalla, L. B., Ghafor, K., \& Mohammed, A. (2019). Testing and modeling the young age compression strength for high workability concrete modified with PCE polymers. Results in Materials, 1, 100004.

47. Qadir W., Ghafor K., and Mohammed A., Characterizing and Modeling the Mechanical Properties of the Cement Mortar Modified with Fly Ash for Various Water-to-Cement Ratios and Curing Times. Advances in the Civil Engineering, DOI: $10.1155 / 2019 / 7013908$.

48. Burhan, L., Ghafor, K., \& Mohammed, A. (2019). Modeling the effect of silica fume on the compression, tensile strengths and durability of NSC and HSC in various strength ranges. Journal of Building Pathology and Rehabilitation, 4(1), 19. 
49. Qadir, W., Ghafor, K., \& Mohammed, A. (2019). Evaluation the effect of lime on the plastic and hardened properties of cement mortar and quantified using Vipulanandan model. Open Engineering, 9(1), 468-480.

50. Burhan, L., Ghafor, K., \& Mohammed, A. (2019). Quantification the effect of microsand on the compression, tensile, flexural strengths, and modulus of elasticity of normal strength concrete. Geomechanics and Geoengineering, 1-19.

51. Mohammed, A., Mahmood, W., \& Ghafor, K. (2020). Shear stress limit, rheological properties and compression strength of cement-based grout modified with polymers. Journal of Building Pathology and Rehabilitation, 5(1), 3.

52. Mohammed, A., Mahmood, W., \& Ghafor, K. (2020). TGA, rheological properties with maximum shear stress and compression strength of cement-based grout modified with polycarboxylate polymers. Construction and Building Materials, 235, 117534.

53. Sihag, P., Jain, P., \& Kumar, M. (2018). Modelling of impact of water quality on recharging rate of storm water filter system using various kernel function-based regression. Modeling earth systems and environment, 4(1), 61-68

54. Saridemir, M. (2009). "Prediction of Compression Strength of Concretes Containing Metakaolin and Silica Fume by Artificial Neural Networks.” Advances in Engineering Software, 40, 350-355.

55. Zain, M. F. M., and Abd, S. M. (2009). "Multiple Regression Model for Compression Strength Prediction of High-Performance Concrete.” Journal of Applied Sciences, 9, 155160. 
56. Emrah Demircan (2009). Modeling the Properties of High-Performance Construction Materials Using Artificial Neural Network and Nonlinear Relation Methods, University of Houston (Master dissertation).

57. Mahmood, W., Mohammed, A., \& Ghafor, K. (2019). Viscosity, yield stress and compression strength of cement-based grout modified with polymers. Results in Materials, 4, 100043.

58. Yildirim, G., Sahmaran, M., \& Ahmed, H. U. (2015). Influence of hydrated lime addition on the self-healing capability of high-volume fly ash incorporated cementitious composites. Journal of Materials in Civil Engineering, 27(6), 04014187.

59. Sihag, P., Jain, P., \& Kumar, M. (2018). Modelling of impact of water quality on recharging rate of storm water filter system using various kernel function-based regression. Modeling earth systems and environment, 4(1), 61-68

60. Saridemir, M. (2009). "Prediction of Compression Strength of Concretes Containing Metakaolin and Silica Fume by Artificial Neural Networks.” Advances in Engineering Software, 40, 350-355.

61. Sihag, P., Tiwari, N.K., and Ranjan, S. (2017a). "Modelling of infiltration of sandy soil using gaussian process regression.” Model. Earth Syst. Environ., 3(3), 1091-1100. doi:10.1007/s40808-017-0357-1

62. Emrah Demircan (2009). Modeling the Properties of High-Performance Construction Materials Using Artificial Neural Network and Nonlinear Relation Methods, University of Houston (Master dissertation). 
593

594

595

596
63. Burhan, L., Ghafor, K., \& Mohammed, A. (2020). Enhancing the Fresh and Hardened Properties of the Early Age Concrete Modified with Powder Polymers and Characterized Using Different Models. Advances in Civil Engineering Materials, 9(1), 227-249. 
Figures
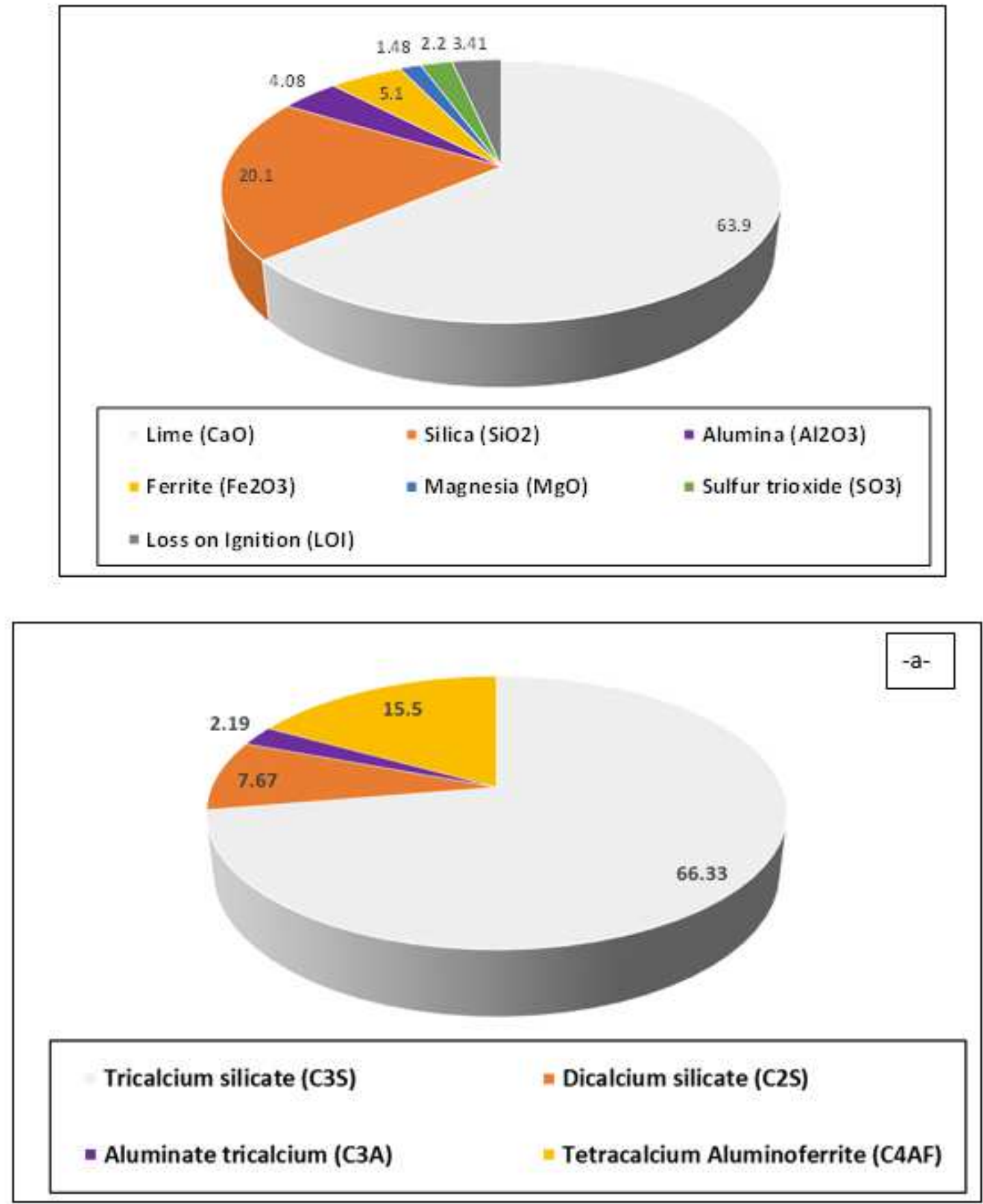

Figure 1

Percentages of (a) Mineralogical composition and (b) Chemical composition of the Ordinary Portland Cement (OPC) 

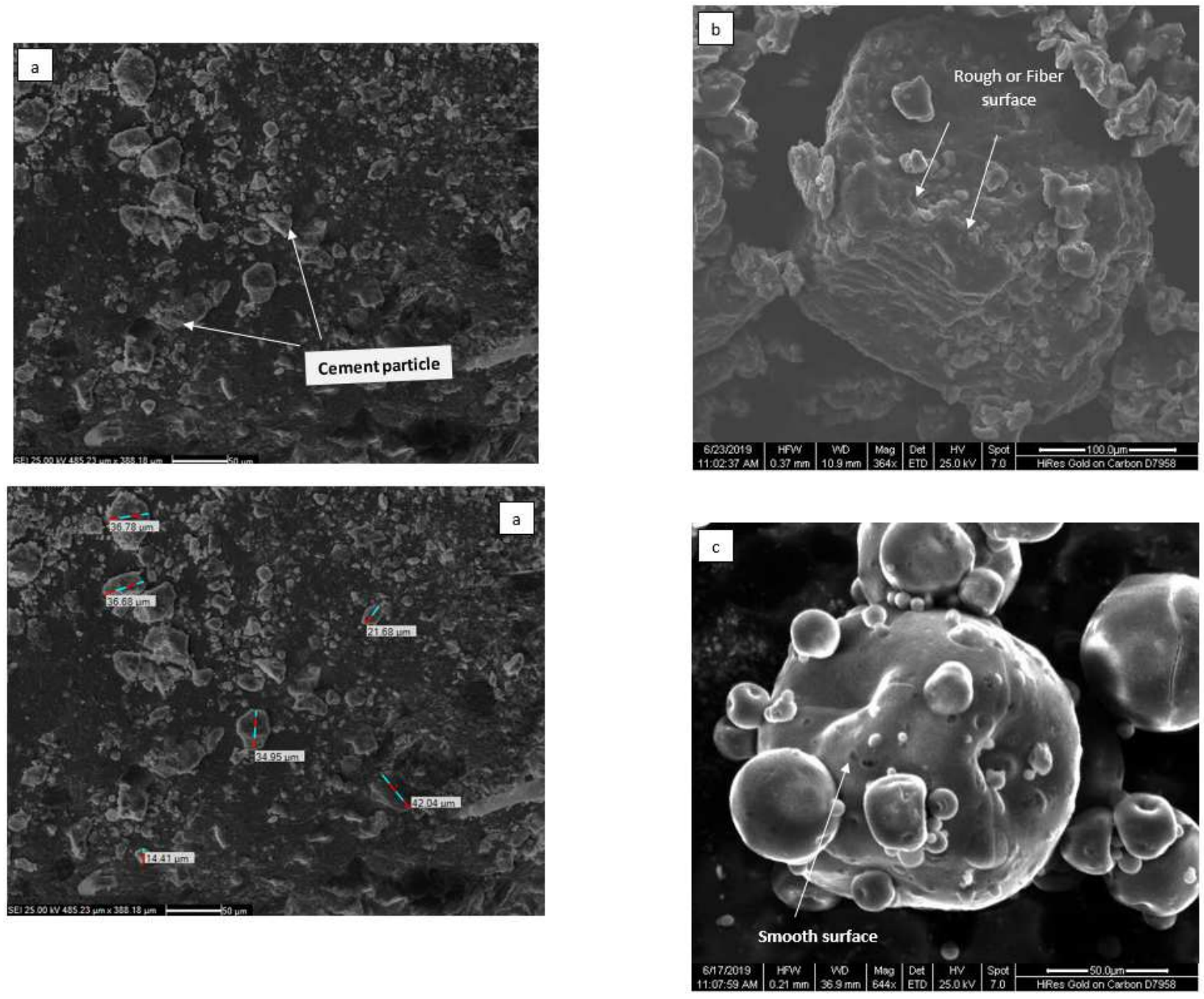

Figure 2

SEM test for (a) Ordinary Portland Cement (OPC) (b) Polymer 1 and (c) Polymer 2 

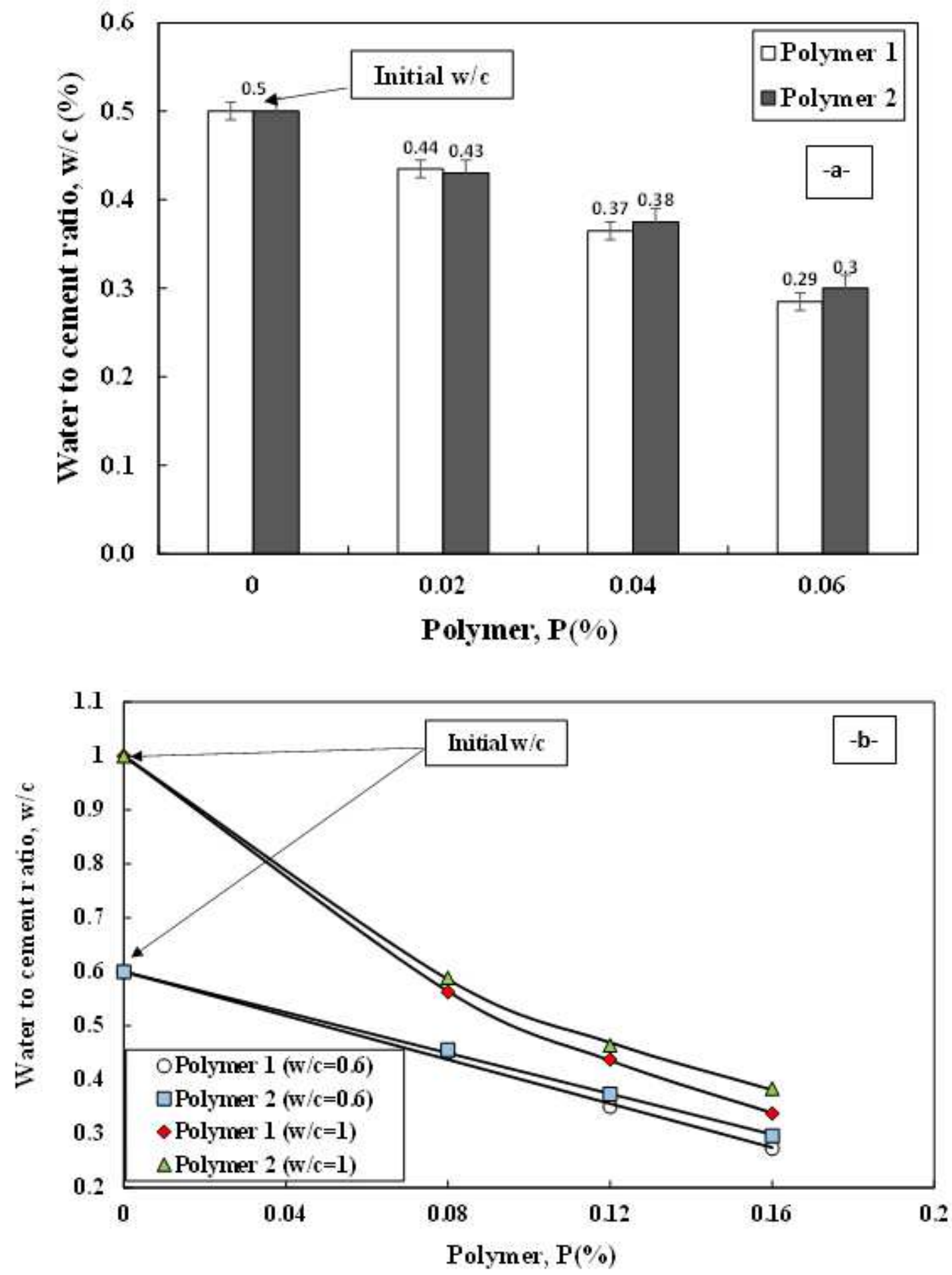

Figure 3

The variation between polymer content and water to cement ratio $(w / c)$ of cement $(a)$ initial $w / c=0.5$ and (b) initial $w / c=0.6$ and 1 


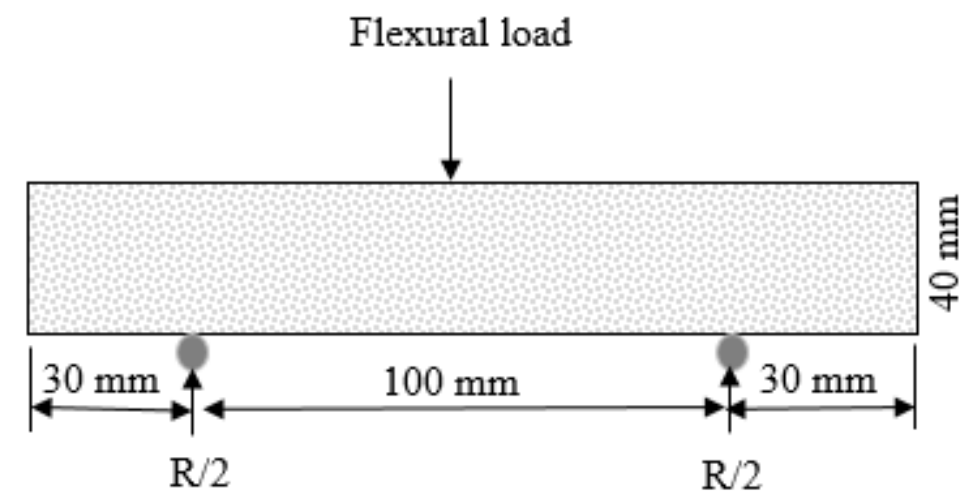

Compression load

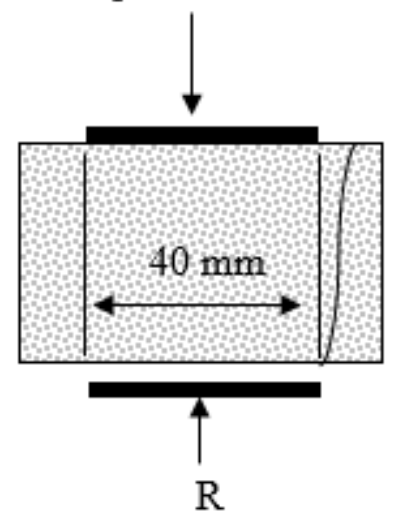

Figure 4

The layout of the cement specimen for a compression test 

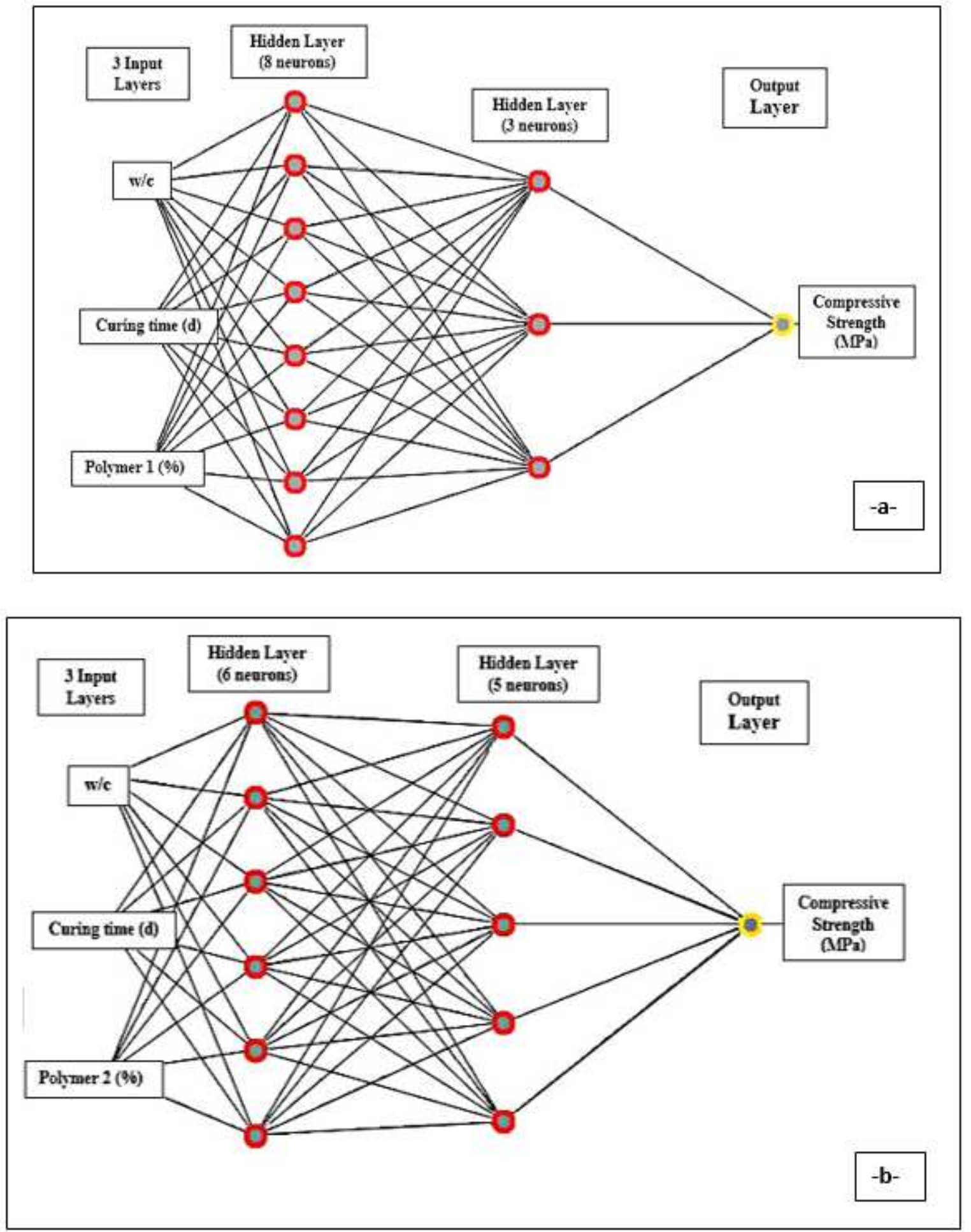

Figure 5

Optimal Network Structures of Neural Network Model (a) cement paste modified with Polymer 1 and (b) cement paste modified with Polymer 2 

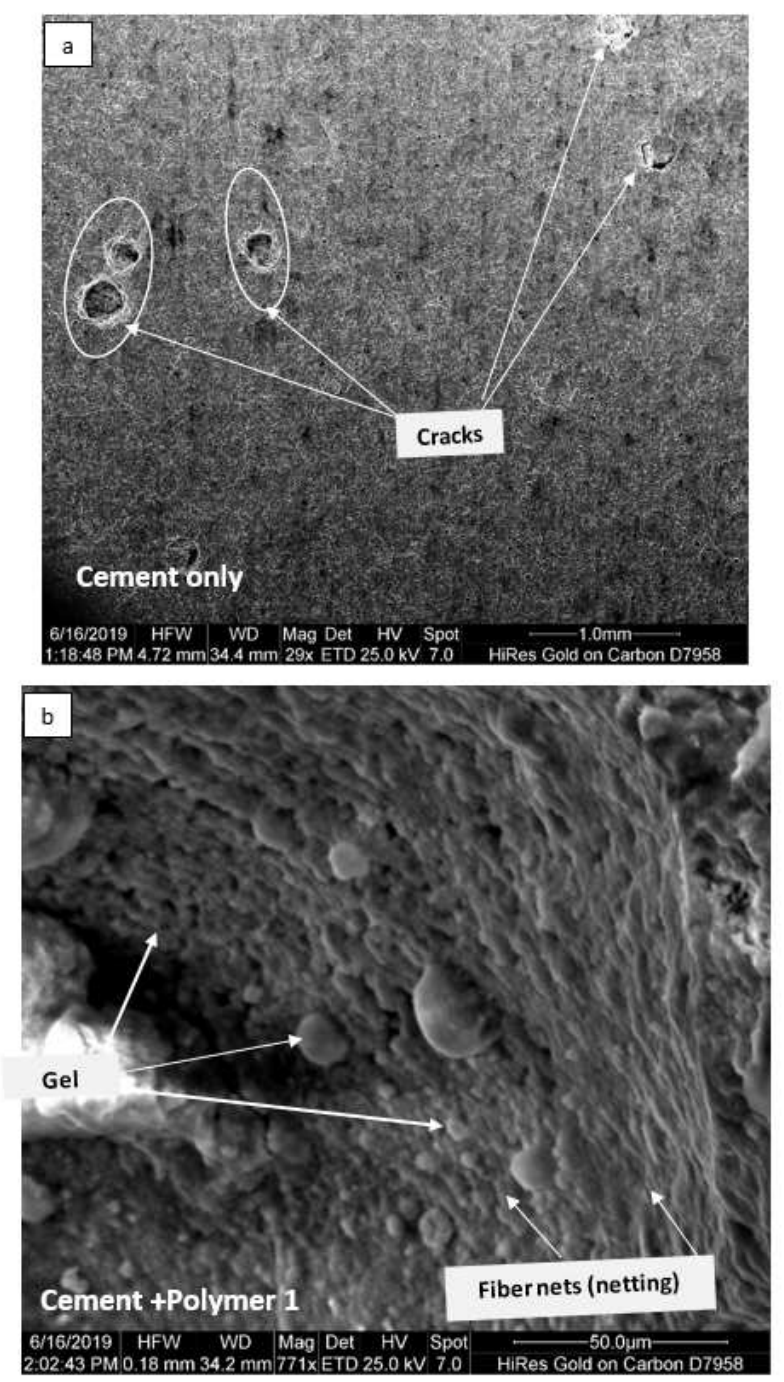

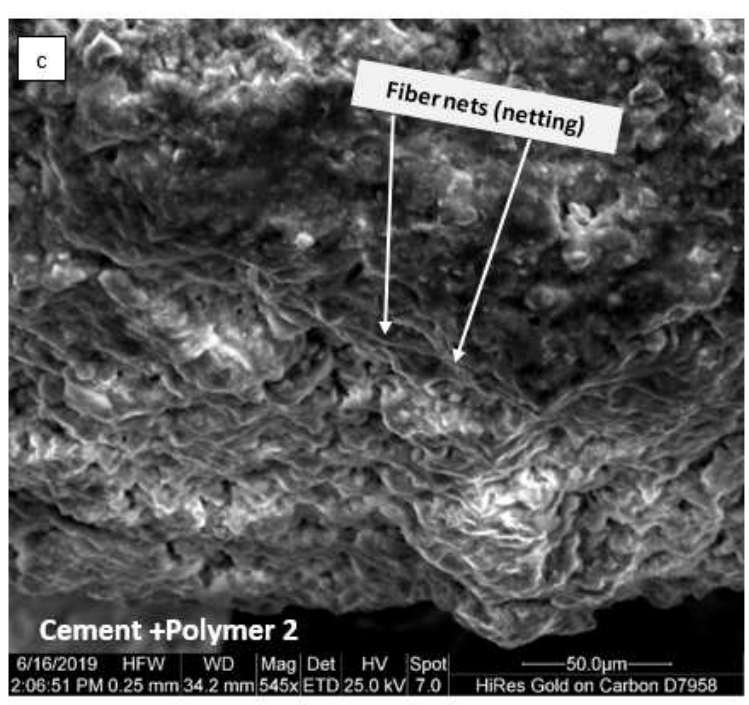

\section{Figure 6}

SEM test for (a) OPC (cement only) (b) Cement modified with $0.06 \%$ of polymer 1 , and (c) Cement modified with $0.06 \%$ of polymer 2 after 7 days of curing 



Figure 7

Variation of the compressive strength of cement paste and polymer contents at initial w/c of 0.5 (a) Polymer 1 and (b) Polymer 2 at different curing times 

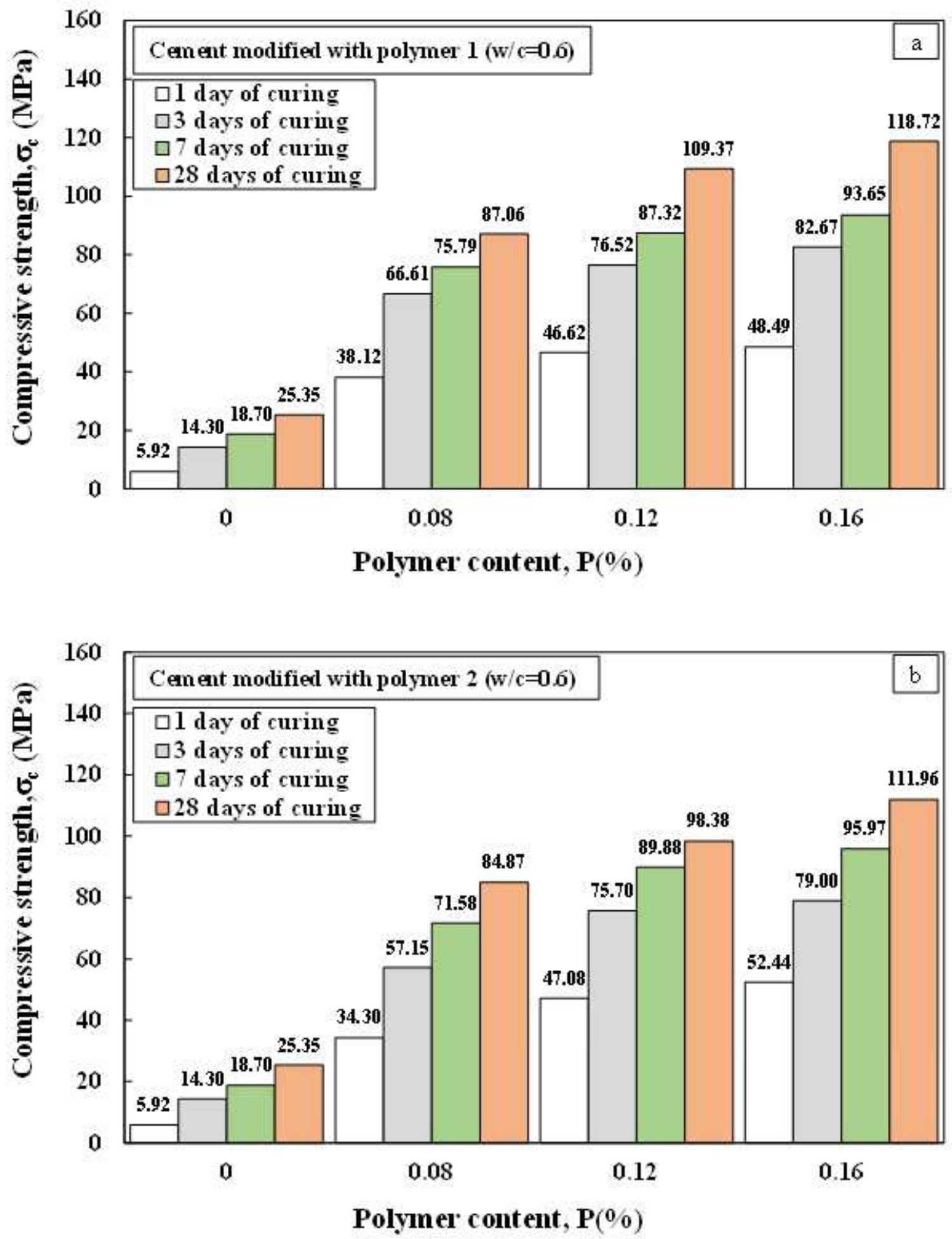

Figure 8

Variation of the compressive strength of cement paste and polymer contents at initial w/c of 0.6 (a) Polymer 1 and (b) Polymer 2 at different curing times 

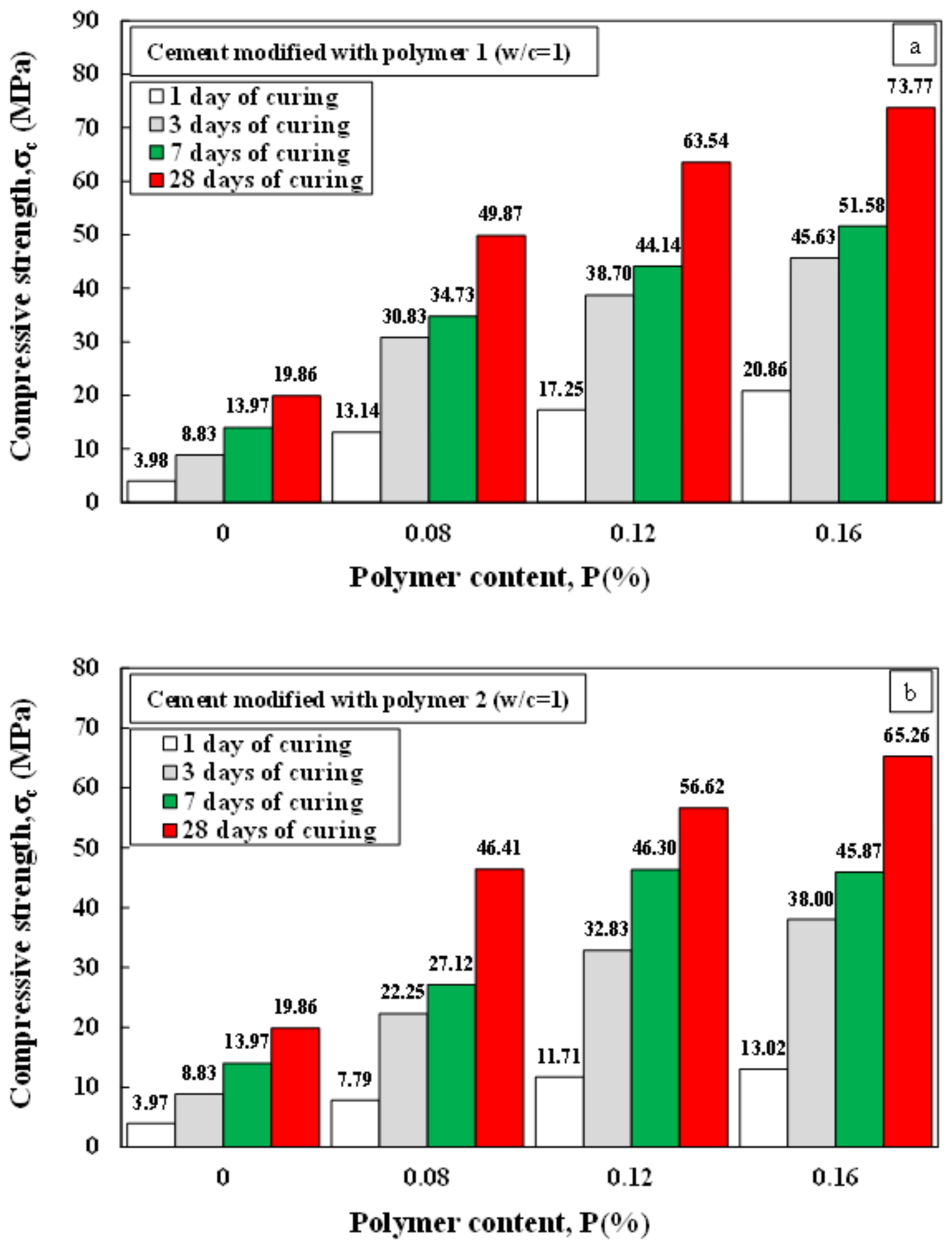

Figure 9

Variation of the compressive strength of cement paste and polymer contents at initial w/c of 1 (a) Polymer 1 and (b) Polymer 2 at different curing times 

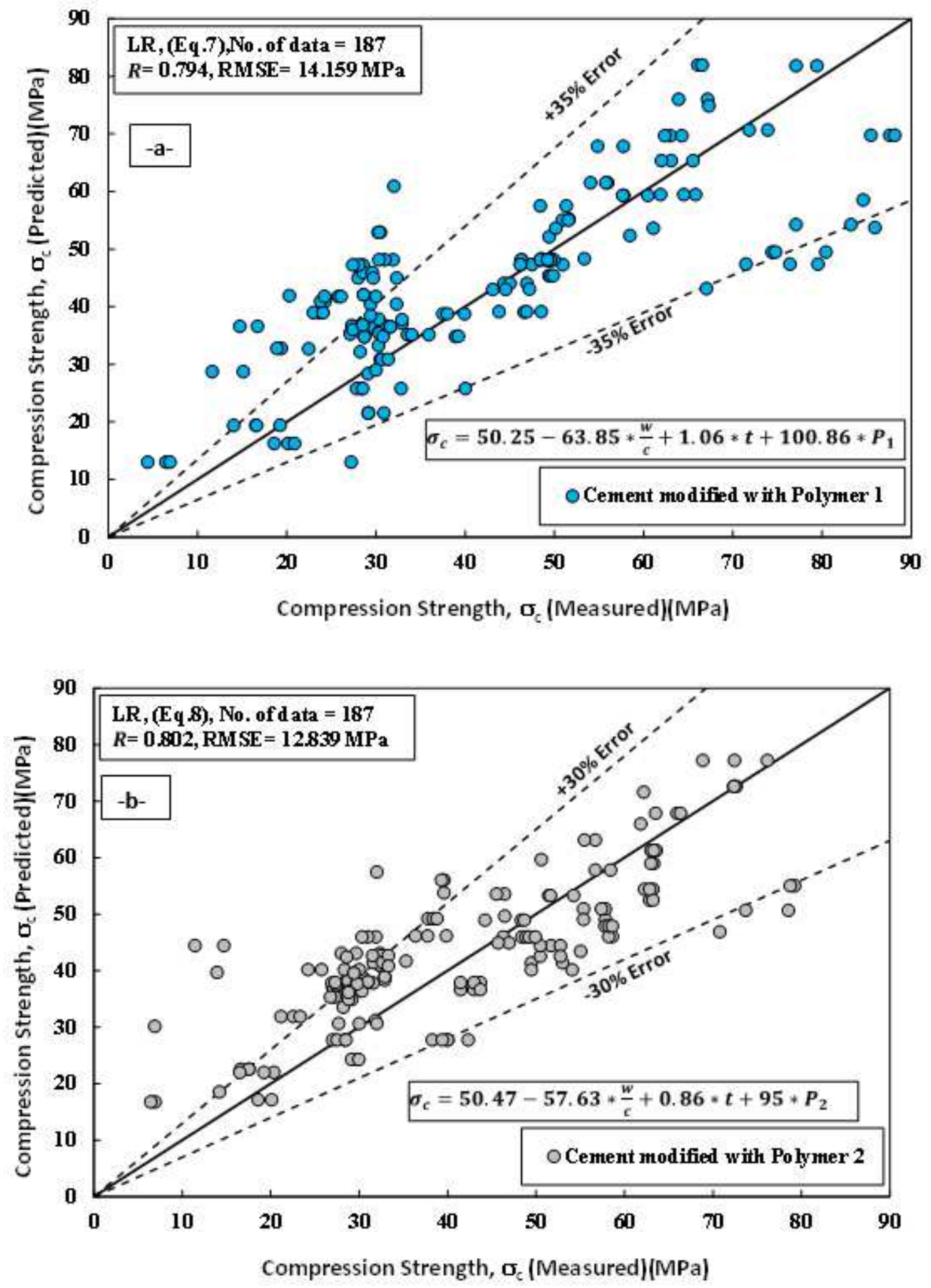

Figure 10

Comparison between measured and predicted the compressive strength of cement paste modified with polymers using Linear Regression Model (LR) for the training data (a) polymer 1, and (b) polymer 2 

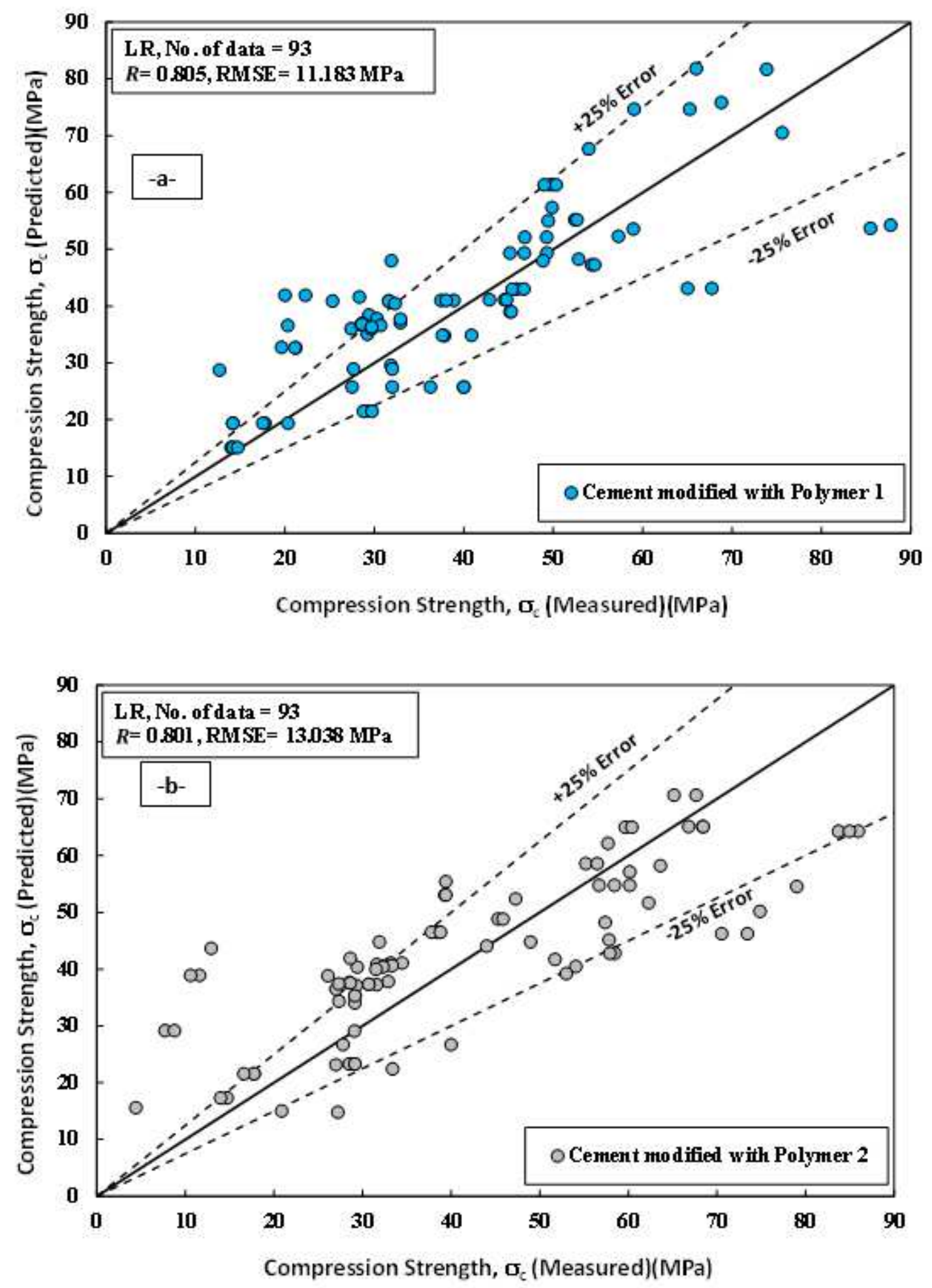

Figure 11

Comparison between measured and predicted the compressive strength of cement paste modified with polymers using Linear Regression Model (LR) for the testing data (a) polymer 1, and (b) polymer 2 

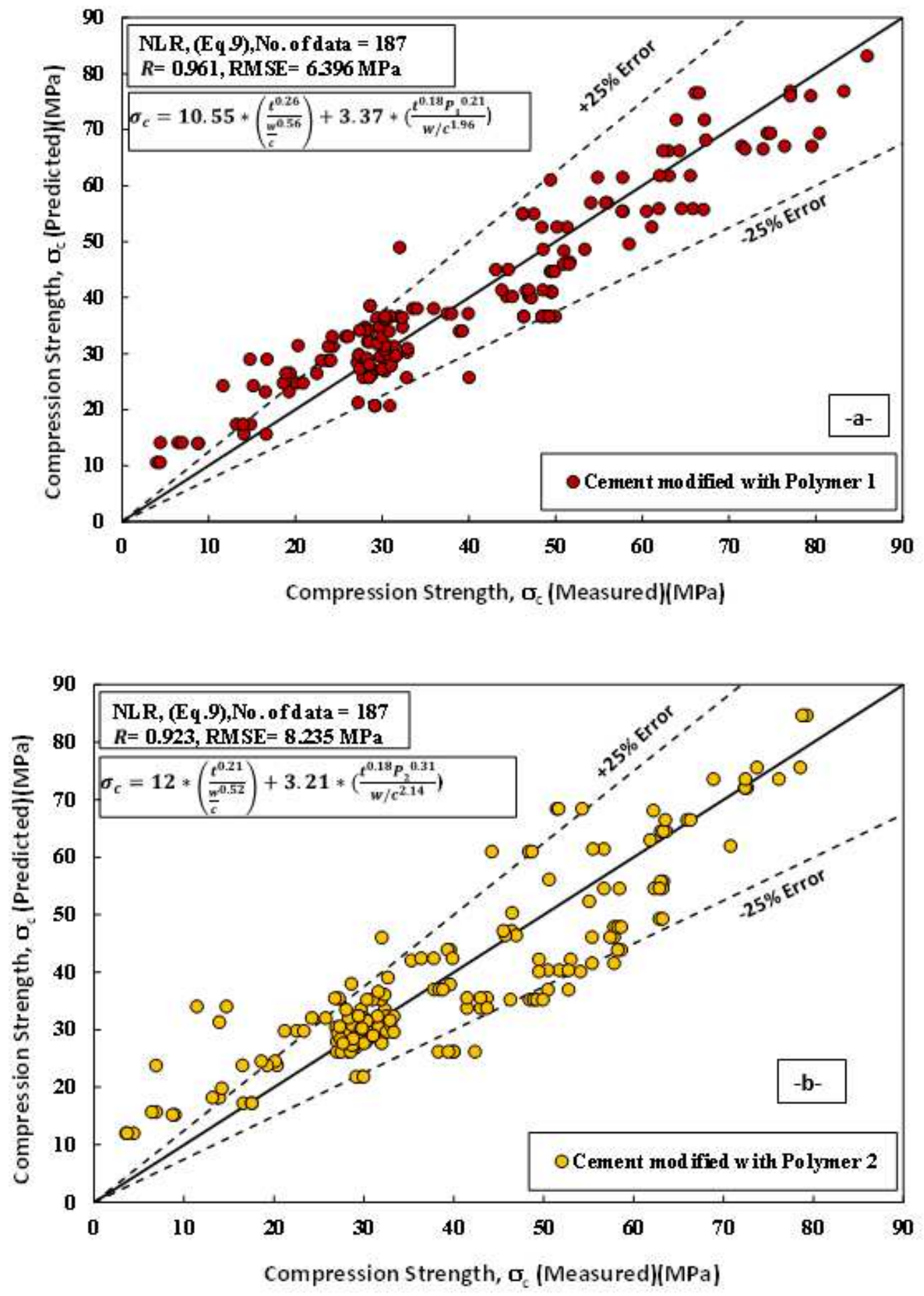

Figure 12

Comparison between measured and predicted the compressive strength of cement paste modified with polymers using Non-Linear Regression Model (NLR) for the training data (a) polymer 1, and (b) polymer 2 

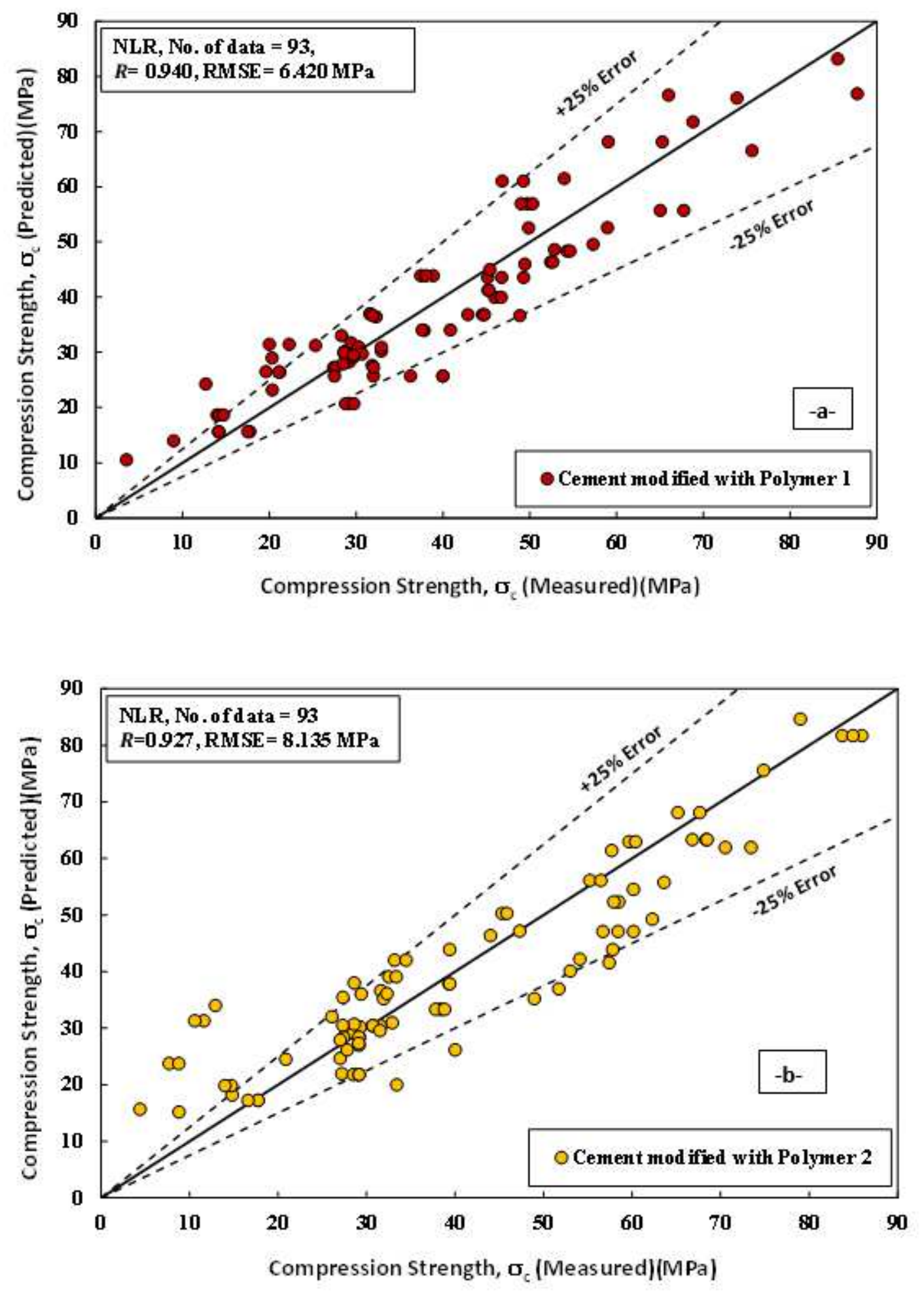

Figure 13

Comparison between measured and predicted the compressive strength of cement paste modified with polymers using Non-Linear Regression Model (NLR) for the resting data (a) polymer 1, and (b) polymer 2 

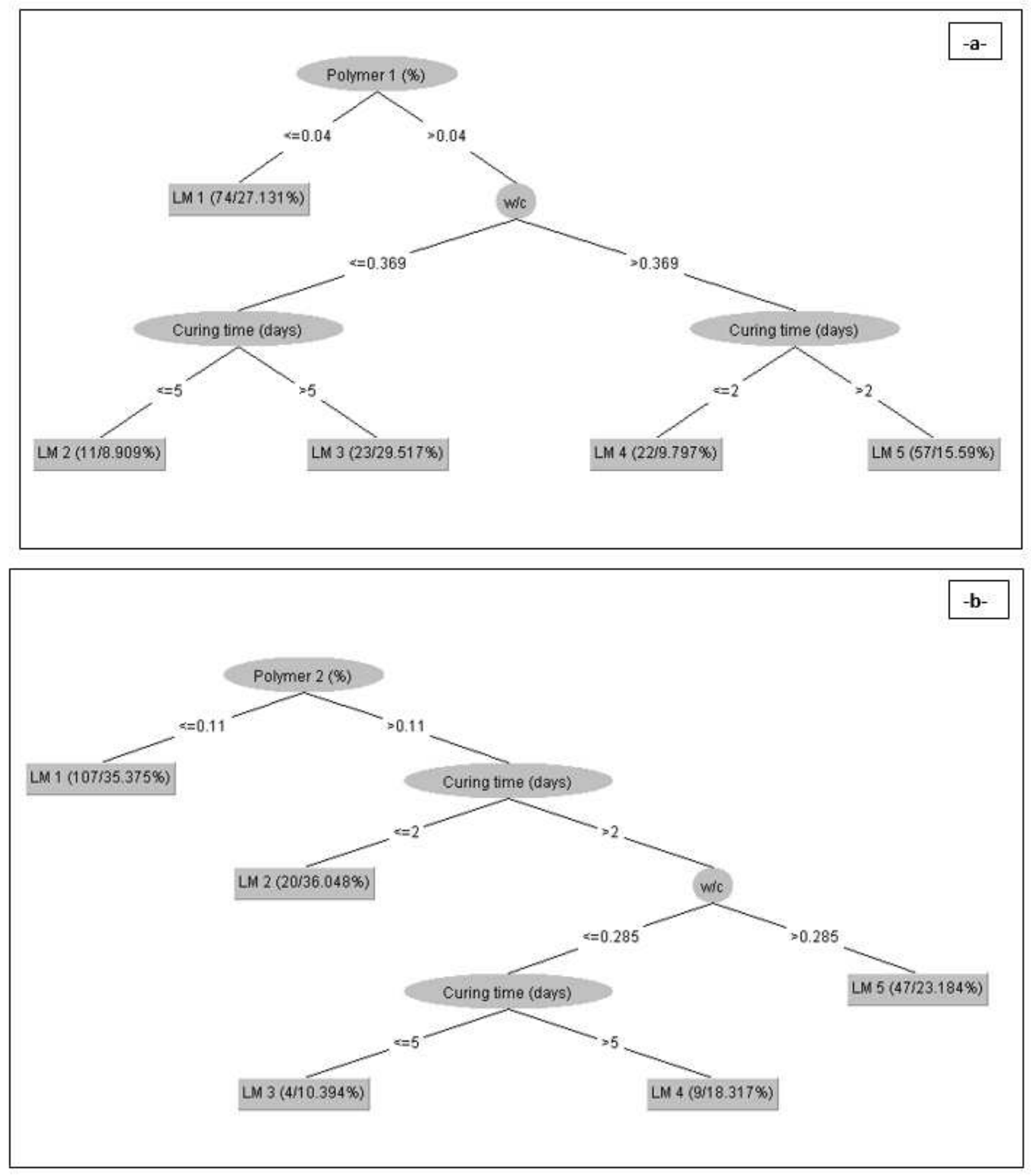

\section{Figure 14}

M5P Pruned model tree (a) cement paste modified with (a) Polymer 1 and (b) cement paste modified with 

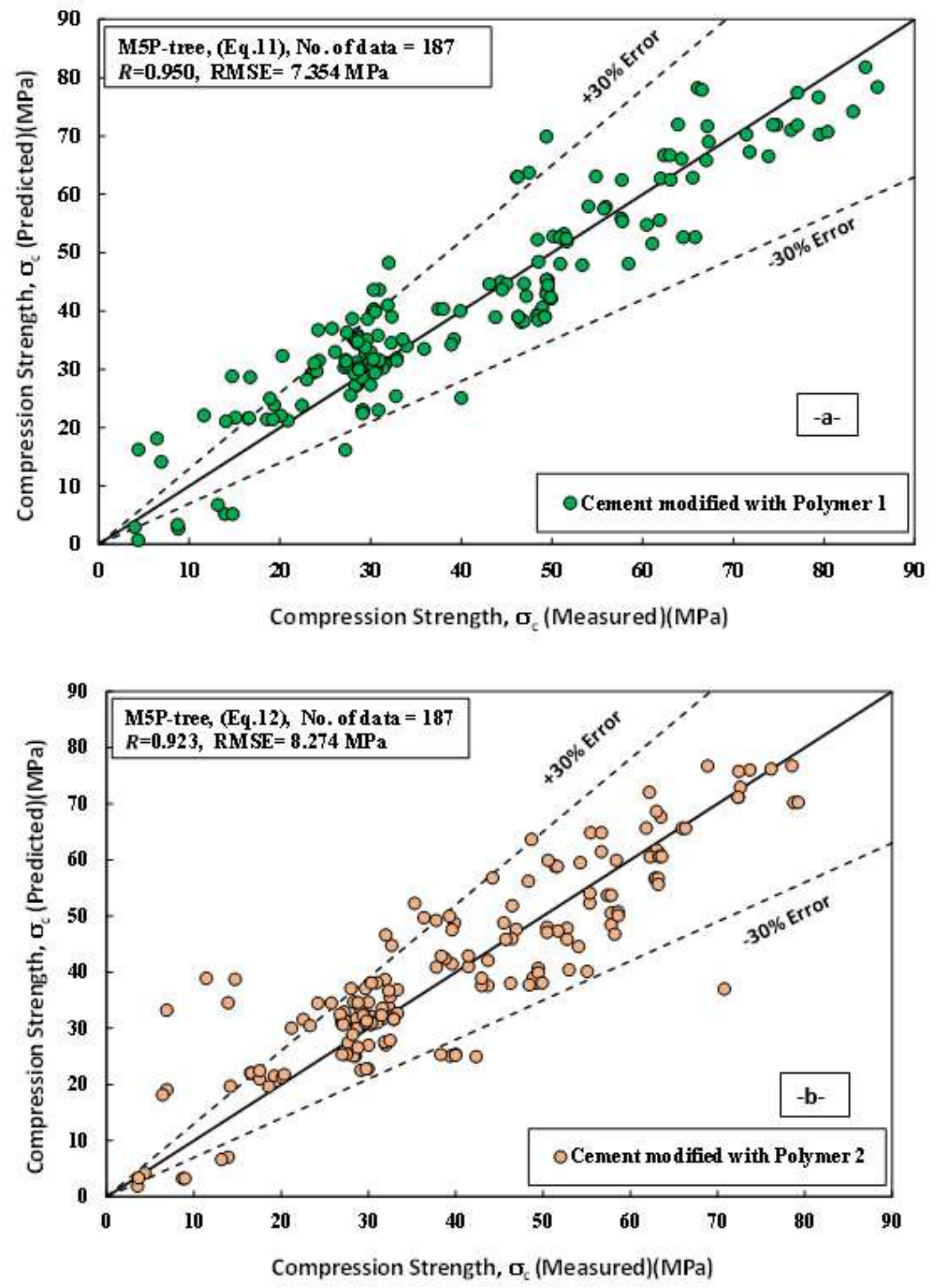

Figure 15

Comparison between measured and predicted the compressive strength of cement paste modified with polymers using M5P-tree Model (M5P) for the training data (a) polymer 1, and (b) polymer 2 

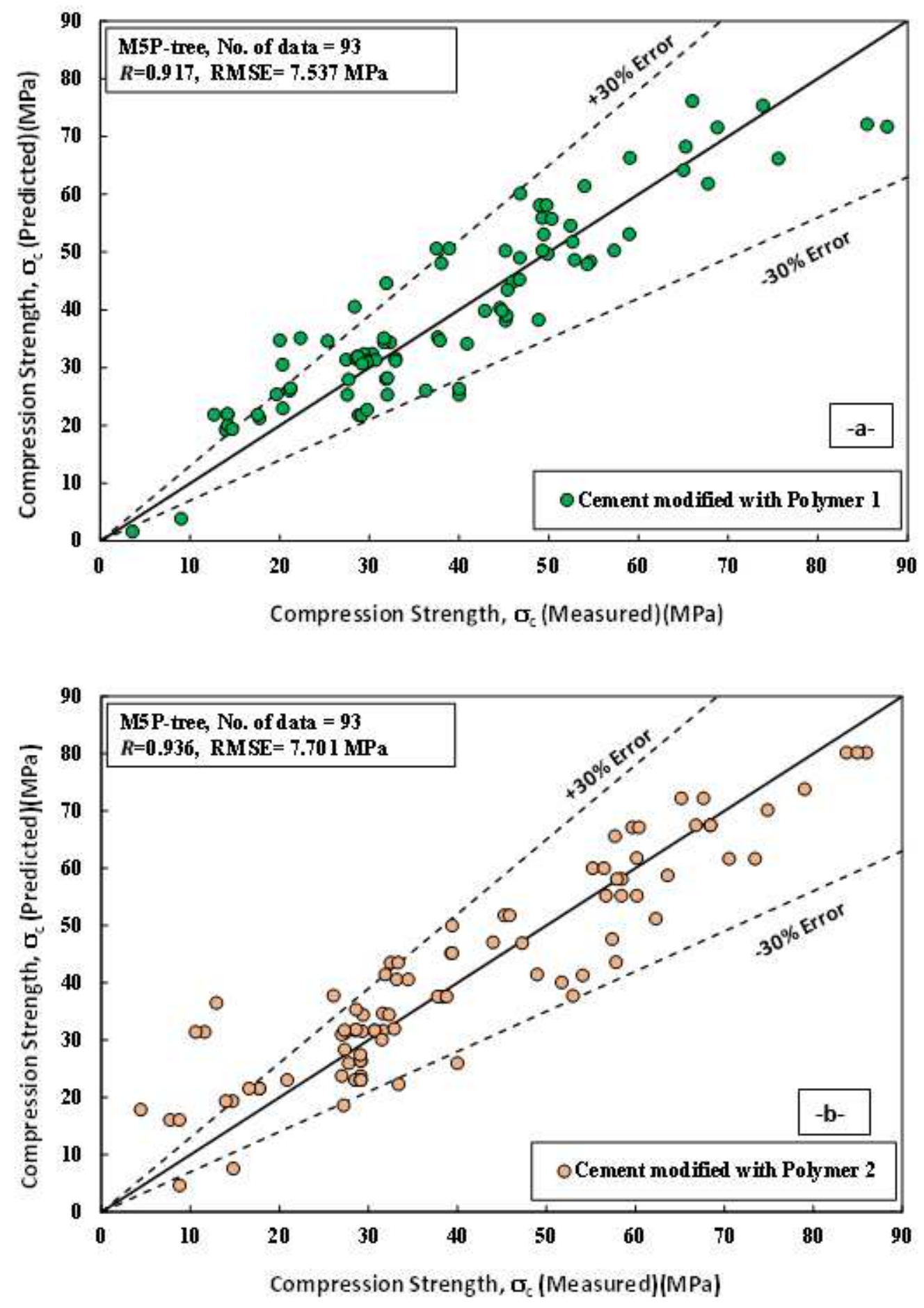

Figure 16

Comparison between measured and predicted the compressive strength of cement paste modified with polymers using M5P-tree Model (M5P) for the testing data (a) polymer 1, and (b) polymer 2 

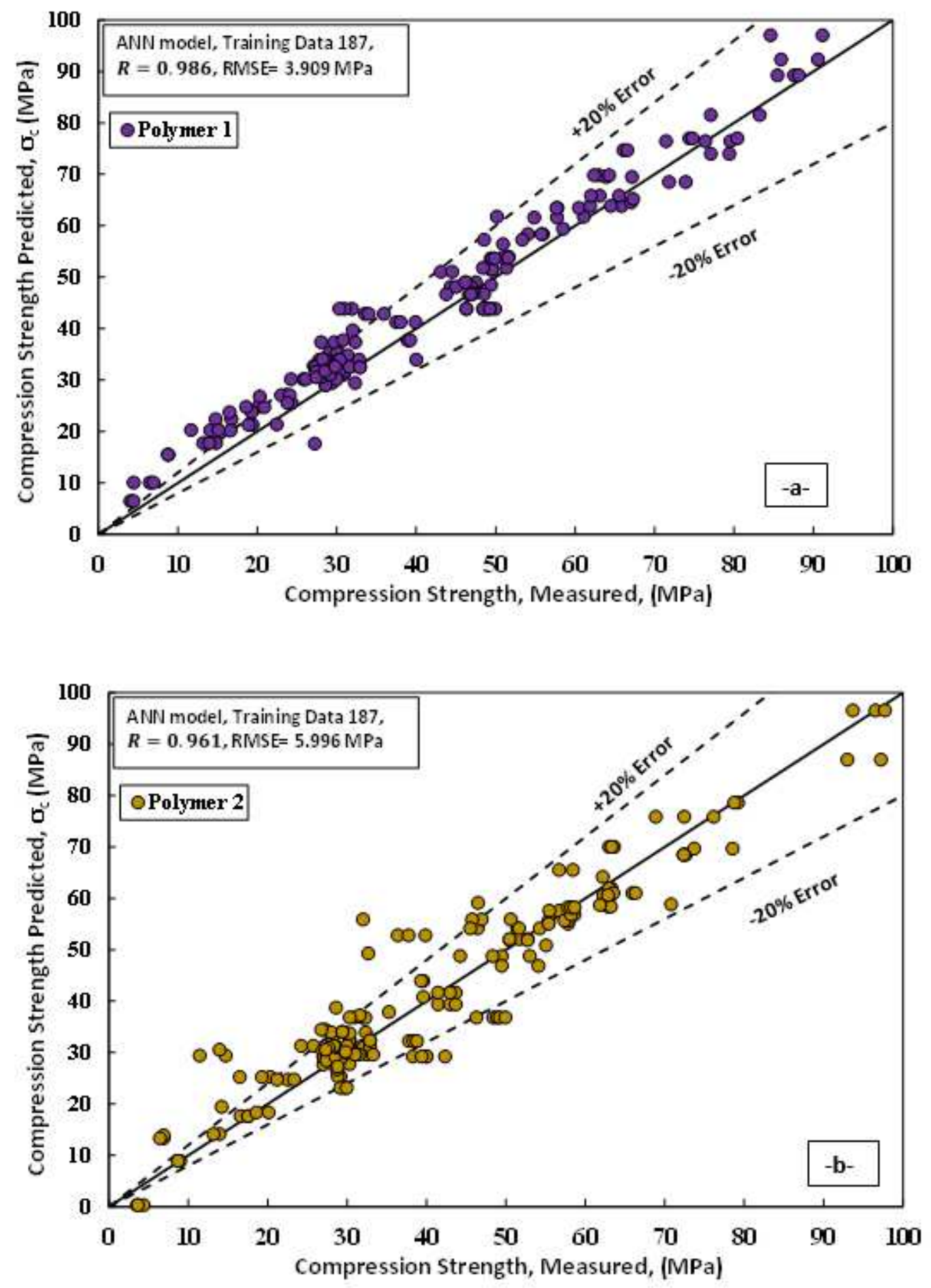

Figure 17

Comparison between measured and predicted the compressive strength of cement paste modified with polymers using ANN Model for the training data (a) polymer 1, and (b) polymer 2 

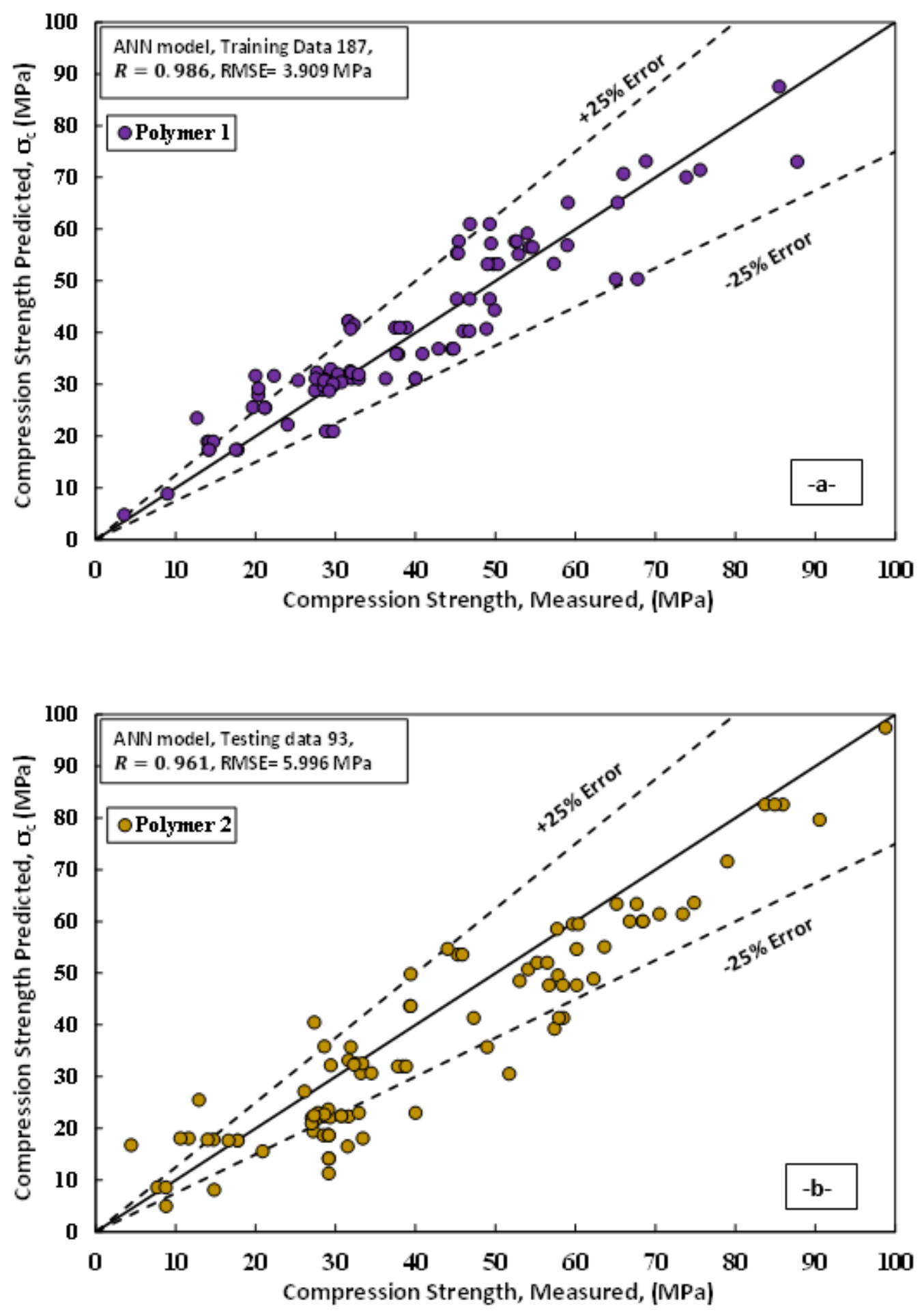

Figure 18

Comparison between measured and predicted the compressive strength of cement paste modified with polymers using ANN Model for the testing data (a) polymer 1, and (b) polymer 2 

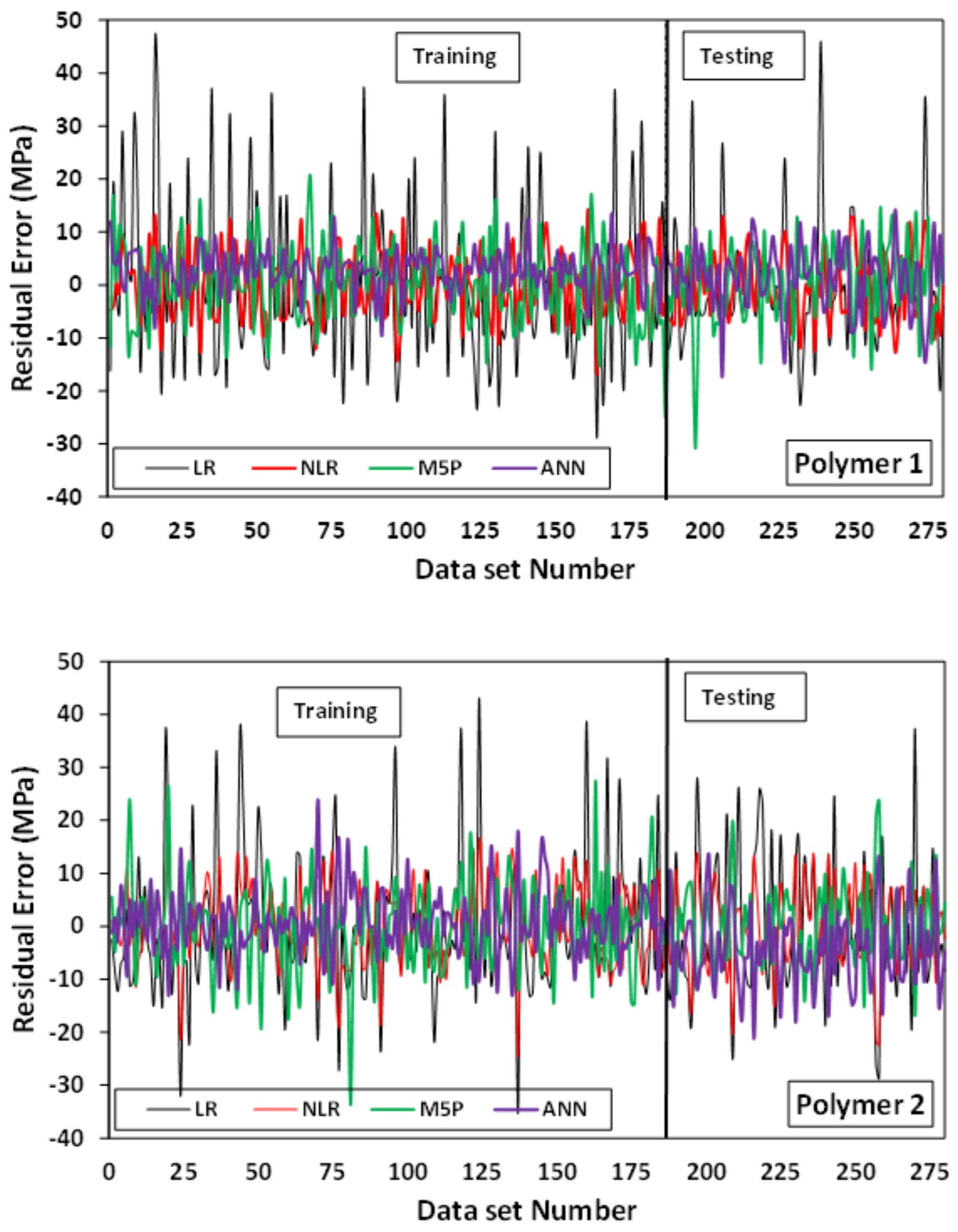

Figure 19

Variation in predictedvalues of compressive strength for cement paste modified with polymers based four different approaches in comparison to observed values 